San Jose State University

SJSU ScholarWorks

Mineta Transportation Institute Publications

$1-2021$

\title{
Using BEAM Software to Simulate the Introduction of On-Demand, Automated, and Electric Shuttles for Last Mile Connectivity in Santa Clara County
}

\author{
Gary Hsueh \\ Mineta Transportation Institute \\ David Czerwinski \\ San Jose State University \\ Cristian Poliziani \\ Mineta Transportation Institute \\ Terris Becker \\ San Jose State University \\ Alexandre Hughes \\ San Jose State University
}

See next page for additional authors

Follow this and additional works at: https://scholarworks.sjsu.edu/mti_publications

Part of the Sustainability Commons, and the Transportation Commons

\section{Recommended Citation}

Gary Hsueh, David Czerwinski, Cristian Poliziani, Terris Becker, Alexandre Hughes, Peter Chen, and Melissa Benn. "Using BEAM Software to Simulate the Introduction of On-Demand, Automated, and Electric Shuttles for Last Mile Connectivity in Santa Clara County" Mineta Transportation Institute Publications (2021). https://doi.org/10.31979/mti.2021.1822

This Report is brought to you for free and open access by SJSU ScholarWorks. It has been accepted for inclusion in Mineta Transportation Institute Publications by an authorized administrator of SJSU ScholarWorks. For more information, please contact scholarworks@sjsu.edu. 


\section{Authors}

Gary Hsueh, David Czerwinski, Cristian Poliziani, Terris Becker, Alexandre Hughes, Peter Chen, and Melissa Benn

This report is available at SJSU ScholarWorks: https://scholarworks.sjsu.edu/mti_publications/343 


\section{SJSU SAN Jose STATIE}

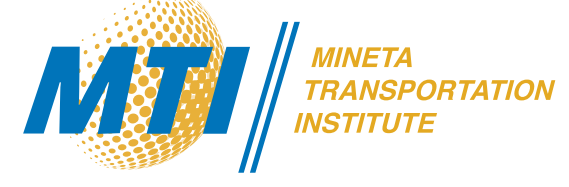

Using BEAM Software to Simulate the Introduction of On-Demand, Automated, and Electric Shuttles for Last Mile Connectivity in Santa Clara County

Gary Hsueh, David Czerwinski, Cristian Poliziani, Terris Becker, Alexandre Hughes, Peter Chen, and Melissa Benn 


\section{Mineta Transportation Institute}

Founded in 1991, the Mineta Transportation Institute (MTI), an organized research and training unit in partnership with the Lucas College and Graduate School of Business at San José State University (SJSU), increases mobility for all by improving the safety, efficiency, accessibility, and convenience of our nation's transportation system. Through research, education, workforce development, and technology transfer, we help create a connected world. MTI leads the Mineta Consortium for Transportation Mobility (MCTM) funded by the U.S. Department of Transportation and the California State University Transportation Consortium (CSUTC) funded by the State of California through Senate Bill 1. MTI focuses on three primary responsibilities:

\section{Research}

MTI conducts multi-disciplinary research focused on surface transportation that contributes to effective decision making. Research areas include: active transportation; planning and policy; security and counterterrorism; sustainable transportation and land use; transit and passenger rail; transportation engineering; transportation finance; transportation technology; and workforce and labor. MTI research publications undergo expert peer review to ensure the quality of the research.

\section{Education and Workforce}

To ensure the efficient movement of people and products, we must prepare a new cohort of transportation professionals who are ready to lead a more diverse, inclusive, and equitable transportation industry. To help achieve this, MTI sponsors a suite of workforce development and education opportunities. The Institute supports educational programs offered by the Lucas Graduate School of Business: a Master of
Science in Transportation Management, plus graduate certificates that include High-Speed and Intercity Rail Management and Transportation Security Management. These flexible programs offer live online classes so that working transportation professionals can pursue an advanced degree regardless of their location.

\section{Information and Technology Transfer}

MTI utilizes a diverse array of dissemination methods and media to ensure research results reach those responsible for managing change. These methods include publication, seminars, workshops, websites, social media, webinars, and other technology transfer mechanisms. Additionally, MTI promotes the availability of completed research to professional organizations and works to integrate the research findings into the graduate education program. MTI's extensive collection of transportation-related publications is integrated into San José State University's world-class Martin Luther King, Jr. Library.

\section{Disclaimer}

The contents of this report reflect the views of the authors, who are responsible for the facts and accuracy of the information presented herein. This document is disseminated in the interest of information exchange. MTI's research is funded, partially or entirely, by grants from the California Department of Transportation, the California State University Office of the Chancellor, the U.S. Department of Homeland Security, and the U.S. Department of Transportation, who assume no liability for the contents or use thereof. This report does not constitute a standard specification, design standard, or regulation. 
Report 20-47

\section{Using BEAM Software to Simulate the Introduction of On-Demand, Automated, and Electric Shuttles for Last Mile Connectivity in Santa Clara County}

Gary Hsueh, https://orcid.org/0000-0002-5753-7365

David Czerwinski, https://orcid.org/0000-0002-6344-6304

Cristian Poliziani, https://orcid.org/0000-0002-7646-1394

Terris Becker, https://orcid.org/0000-0001-9280-3895

Alexandre Hughes, https://orcid.org/0000-0001-9215-4434

Peter Chen, https://orcid.org/0000-0001-7111-3035

Melissa Benn, https://orcid.org/0000-0002-8038-3122

January 2021 


\section{TECHNICAL REPORT \\ DOCUMENTATION PAGE}

\begin{tabular}{|c|c|c|c|}
\hline $\begin{array}{l}\text { 1. Report No. } \\
\quad 20-47\end{array}$ & 2. Government Accession No. & \multicolumn{2}{|c|}{ 3. Recipient's Catalog No. } \\
\hline & \multicolumn{2}{|l|}{ 5. Report Date } \\
\hline \multicolumn{2}{|c|}{$\begin{array}{l}\text { Using BEAM Software to Simulate the Introduction of On-Demand, } \\
\text { Automated, and Electric Shuttles for Last Mile Connectivity in } \\
\text { Santa Clara County }\end{array}$} & \multicolumn{2}{|c|}{ 6. Performing Organization Code } \\
\hline \multicolumn{2}{|c|}{$\begin{array}{l}\text { Gary Hsueh, David Czerwinski, Cristian Poliziani, Terris Becker, Alexandre } \\
\text { Hughes, Peter Chen, and Melissa Benn }\end{array}$} & \multicolumn{2}{|c|}{$\begin{array}{l}\text { 8. Performing Organization Report } \\
\text { CA-MTI-1822 }\end{array}$} \\
\hline \multirow{2}{*}{\multicolumn{2}{|c|}{$\begin{array}{l}\text { 9. Performing Organization Name and Address } \\
\text { Mineta Transportation Institute }\end{array}$}} & \multicolumn{2}{|c|}{ 10. Work Unit No. } \\
\hline & & \multicolumn{2}{|c|}{$\begin{array}{l}\text { 11. Contract or Grant No. } \\
69 \mathrm{~A} 3551747127\end{array}$} \\
\hline \multicolumn{2}{|l|}{ 12. Sponsoring Agency Name and Address } & \multicolumn{2}{|c|}{ 13. Type of Report and Period Covered } \\
\hline \multicolumn{2}{|c|}{$\begin{array}{l}\text { U.S. Department of Transportation, Office of the Assistant Secretary for Research } \\
\text { and Technology, University Transportation Centers Program } \\
1200 \text { New Jersey Avenue, SE, Washington, DC } 20590\end{array}$} & \multicolumn{2}{|c|}{ 14. Sponsoring Agency Code } \\
\hline \multicolumn{4}{|l|}{$\begin{array}{l}\text { 15. Supplemental Notes } \\
\text { DOI: } 10.31979 / \mathrm{mti} .2021 .1822\end{array}$} \\
\hline \multicolumn{4}{|c|}{$\begin{array}{l}\text { 16. Abstract } \\
\text { Despite growing interest in low-speed automated shuttles, pilot deployments have only just begun in a few places in the U.S., } \\
\text { and there is a lack of studies that estimate the impacts of a widespread deployment of automated shuttles designed to } \\
\text { supplement existing transit networks. This project estimated the potential impacts of automated shuttles based on a } \\
\text { deployment scenario generated for a sample geographic area: Santa Clara County, California. The project identified sample } \\
\text { deployment markets within Santa Clara County using a GIS screening exercise; tested the mode share changes of an automated } \\
\text { shuttle deployment scenario using BEAM, an open-source beta software developed at the Lawrence Berkeley National } \\
\text { Laboratory to run traffic simulations with MATSim; elaborated the model outputs within the R environment; and then } \\
\text { estimated the related impacts. The main findings have been that the BEAM software, despite still being in its beta version, } \\
\text { was able to model a scenario with the automated shuttle service: this report illustrates the potential of the software and the } \\
\text { lessons learned. Regarding transportation aspects, the model estimated automated shuttle use throughout the county, with a } \\
\text { higher rate of use in the downtown San José area. The shuttles would be preferred mainly by people who had been using } \\
\text { gasoline-powered ride hail vehicles for A-to-B trips or going to the bus stop, as well as walking trips and a few car trips directed } \\
\text { to public transport stops. As a result, the shuttles contributed to a small decrease in emissions of air pollutants, provided a } \\
\text { competitive solution for short trips, and increased the overall use of the public transport system. The shuttles also presented a } \\
\text { solution for short night trips-mainly between midnight and } 2 \text { am-when there are not many options for moving between } \\
\text { points A and B. The conclusion is that the automated shuttle service is a good solution in certain contexts and can increase } \\
\text { public transit ridership overall. }\end{array}$} \\
\hline $\begin{array}{l}\text { 17. Key Words } \\
\text { Electric vehicles, Intelligent vehicles, Transit } \\
\text { accessibility, On-demand transit, Micro } \\
\text { transit, Sustainable transportation, Transit } \\
\text { oriented development }\end{array}$ & $\begin{array}{l}\text { 18. Distribution Statement } \\
\text { No restrictions. This document } \\
\text { National Technical Informatio }\end{array}$ & $\begin{array}{l}\text { is available to the } 1 \\
\text { Service, Springfie }\end{array}$ & $\begin{array}{l}\text { lic through The } \\
\text { VA } 22161\end{array}$ \\
\hline $\begin{array}{l}\text { 19. Security Classif. (of this report) } \\
\text { Unclassified }\end{array}$ & $\begin{array}{l}\text { 20. Security Classif. (of this page) } \\
\text { Unclassified }\end{array}$ & $\begin{array}{l}\text { 21. No. of Pages } \\
35\end{array}$ & 22. Price \\
\hline
\end{tabular}

Form DOT F 1700.7 (8-72) 
Copyright (C) 2021

\section{by Mineta Transportation Institute}

All rights reserved.

DOI: $10.31979 / \mathrm{mti} .2021 .1822$

Mineta Transportation Institute College of Business San José State University San José, CA 95192-0219

Tel: (408) 924-7560

Fax: (408) 924-7565

Email: mineta-institute@sjsu.edu

transweb.sjsu.edu/research/1822 


\section{ACKNOWLEDGMENTS}

The authors would like to thank Professor Richard Kos of San José State University and several students from his Fall 2018 Advanced GIS Class-Frank Arellano, Matthew Moore, and Michael Mulligan-for their background research and GIS analysis. The authors also thank Colin Sheppard of Lawrence Berkeley National Laboratory and his team of developers for their support with BEAM. The authors thank MTI staff, including Executive Director Karen Philbrick, PhD, Deputy Executive Director Hilary Nixon, PhD, editing staff, and peer reviewers for thoughtful comments and support. 


\section{CONTENTS}

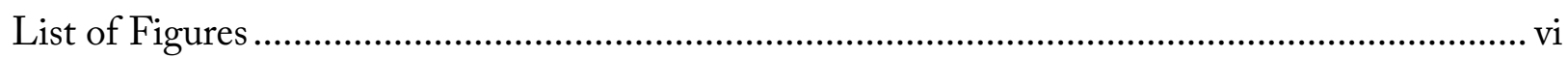

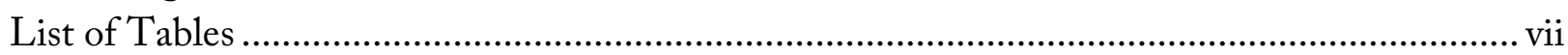

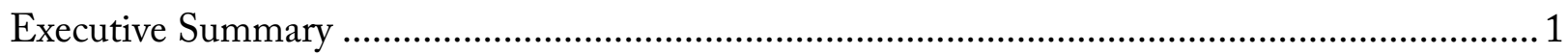

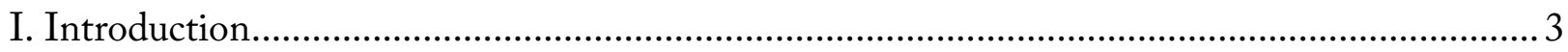

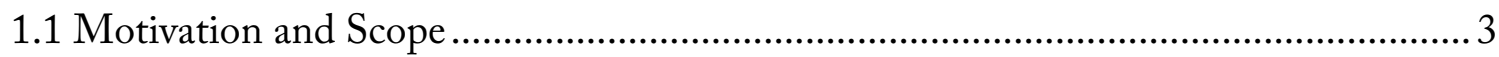

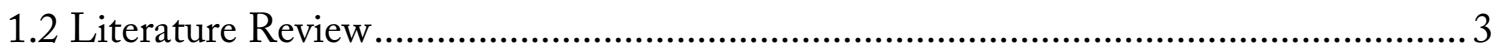

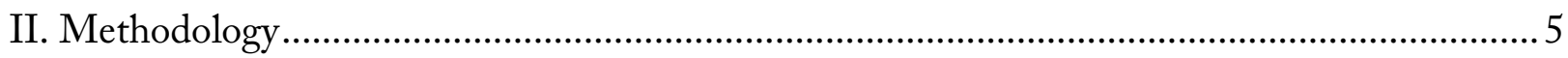

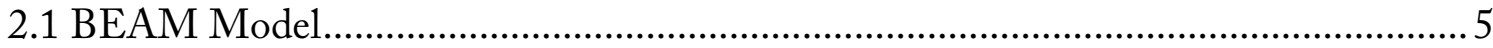

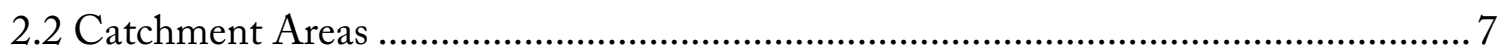

2.3 Sensitivity Analysis and Assumed Parameters........................................................ 9

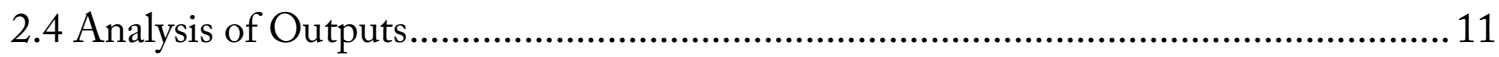

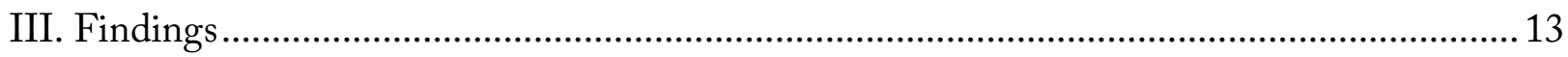

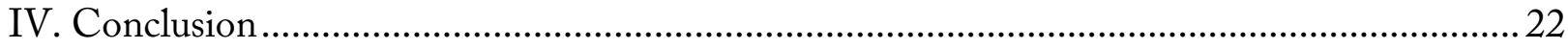

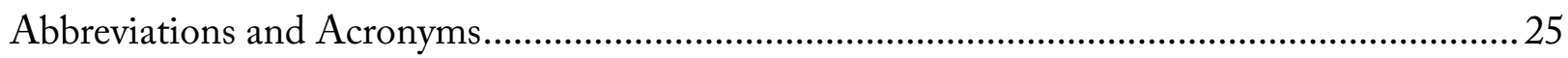

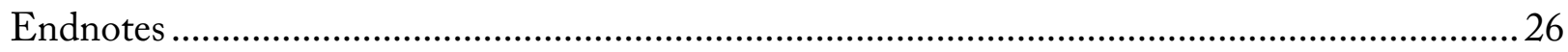

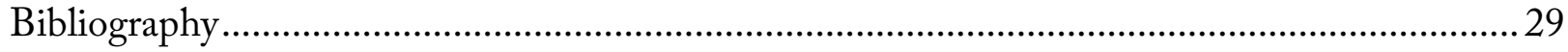

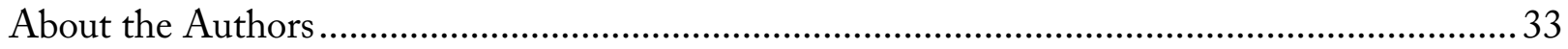




\section{LIST OF FIGURES}

Figure 1. Catchment Areas for Automated Shuttles in Santa Clara County.................................

Figure 2. Heat Map of Departures and Arrivals by Time of Day .................................................13

Figure 3. Heat Map of Trips involving Santa Clara County …………………………...............14

Figure 4. Relative Frequency Distribution of Departure Time of Automated

Shuttles during the Day, Compared with the Usage of Cars, Other Ride Hails, and Public Transport Service

Figure 5. Spatial Distribution of Departures of Automated Shuttles' Trips in Santa Clara County When Using a 10\% Population Sample ................................................21 


\section{LIST OF TABLES}

Table 1. Statistics of Trips Carried Out in the Baseline Scenario ................................................13

Table 2. Statistics of Trips Departing from or Arriving to Santa Clara County ...........................14

Table 3. Mode Share of Trips Involving Santa Clara County in the Baseline Scenario................15

Table 4. Mode Share of Trips Involving Santa Clara County in the Automated

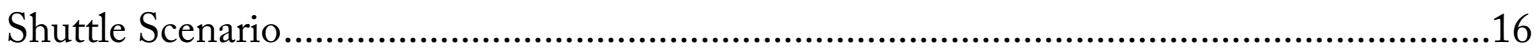

Table 5. Statistics of Trips Involving Santa Clara County in the Baseline Scenario

per Transport Mode Used .................................................................................................16

Table 6. Statistics of Trips Involving Santa Clara County in the Automated Shuttle Scenario per Transport Mode Used ..................................................................................17

Table 7. Statistics of Vehicles Involving Santa Clara County in the Baseline Scenario

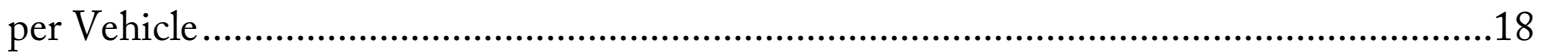

Table 8. Statistics of Vehicles Involving Santa Clara County in the Automated Shuttle Scenario per Vehicle ..............................................................................................18

Table 9. Statistics of Trips Involving Santa Clara County in the Baseline Scenario by Fuel Type

Table 10. Statistics of Trips Involving Santa Clara County in the Automated Shuttle Scenario by Fuel Type 


\section{Executive Summary}

The present study investigates the potential of automated shuttles that are meant to provide first and last mile connections to higher-order public transit services. The service is assumed to be automated, on-demand, and low-speed - up to $40 \mathrm{~km} / \mathrm{h}(25 \mathrm{mph})$ — and each vehicle is confined to operate within a round catchment area centered on a high-quality bus stop or transit station, characterized by a high frequency of buses or trains. The first intent of the study is to simulate and estimate the impacts of such a transport system in Santa Clara County. The second goal is to report the experience of conducting research using the beta software BEAM, which allows one to perform a traffic simulation with MATSim, which is mesoscopic in scale-characterized by an intermediate level of detail between the classical macro-approach and the recent micro-approachand agent-based, in which an artificial population is reproduced, and each agent can autonomously make their own travel decisions and interact with other agents. The software was developed at Lawrence Berkeley National Laboratory and a baseline scenario was calibrated by the BEAM development team to simulate the nine-county San Francisco Bay Area region, ${ }^{1}$ which includes the study area of Santa Clara County.

A literature review provides a starting point for understanding the potential of the automated shuttles and establishes the range of ideal parameters for the study - mainly regarding maximum speed, radius of catchment area, positions of catchment areas, and so on.

Next, the report explains the methodology used for achieving the main goals. Attention is particularly focused on the pros and cons of using the BEAM software, describing what the team learned by using it and providing suggestions to future users. In the same chapter, the authors describe the methodology for defining the catchment areas and the sensitivity analysis used to calibrate certain parameters of the model: radius of the catchment areas, pricing of the automated shuttle service, time of simulation, initial position of the shuttles inside the catchment areas, vehicle size, and maximum speed. These parameters were calibrated by running many simulations of scaled-down scenarios and with the support of the BEAM developers' group. The last part of the chapter describes the methodology used for analyzing the outputs of the model. In that section, the authors explain the processes used in the software $\mathrm{R}$, in case future researchers want to analyze the BEAM outputs.

The entire nine-county San Francisco Bay Area was simulated, with and without the deployment

of the automated shuttles. The results were processed, filtered for the trips involving Santa Clara County, and then illustrated in the last chapter. The main findings are:

- The BEAM model can simulate the automated shuttles in the calibrated model of the whole Bay Area. The pro and cons are discussed, as are suggestions for future users. 
- The automated shuttles are used by many travelers, even if the impact of this mode of transport is eclipsed by the overwhelming presence of cars.

- Some trips with automated shuttles are registered during the night-mainly between midnight and $2 \mathrm{am}$ - due to the lack of other good options for users, increasing the accessibility of travel during night hours.

- The trips with automated shuttles are distributed across the county, with a higher use in the downtown San José area.

- The automated shuttles replace mainly ride hail vehicles for point-to-point service within the catchment areas and ride hail vehicles directed to bus stops but also displace some walking trips.

- The availability of automated shuttles leads to more trips on public transport but the same number of car trips.

- The average length of all trips on the automated shuttles is $6 \mathrm{~km}$, with an average travel time of 10 minutes.

- Public transport trips that include an automated shuttle leg are approximately an hour long, validating the use of the automated shuttles for short, "first or last mile" connections to other transit services that the travelers use to complete the remainder of their trip.

- The automated electric shuttles reduce the number of gas trips.

The results of this study support the wide-scale adoption of on-demand, flexible-route shuttles to address the first/last mile problem and improve accessibility to high-quality public transit throughout Santa Clara County. Communities, particularly those lacking many fixed-route transit services, can look to on-demand shuttles as an alternative approach. Regional and county transportation agencies can use these high-level conclusions as a basis to support more robust scenario testing and planning with their official models. The BEAM model is intriguing. Given the beta status of the software and user interface limitations, it is not recommended for practitioners to use "off the shelf," but owing to its Bay Area calibration, can be applied to other Bay Area counties for high-level planning of similar scenarios. 


\section{Introduction}

\subsection{Motivation and Scope}

The growing interest in automated shuttles as a method for providing first and last mile connections to public transport services, together with the scarcity of studies and pilot deployments based on such a transportation mode, led to the idea of using a traffic simulation to model a range of scenarios with low-speed automated vehicles in Santa Clara County, California. The main scope of the project is to evaluate the impacts of this mode of transport as well as to test the potential and the feasibility of using the BEAM software developed by the Lawrence Berkeley National Laboratory. BEAM is able to simulate the daily traffic in the nine-county San Francisco Bay Area region, including Santa Clara County, by means of extending the functions of the traffic microsimulator MATSim. BEAM is mesoscopic in scale, characterized by an intermediate level of detail between the classical macro-approach and more recent micro-approach, and agent-based, in which an artificial population is reproduced, and each user can autonomously make their own travel decisions and interact with other agents.

\subsection{Literature Review}

The main weakness of a public transport network is clearly represented by its accessibility, mainly for low-density areas where fixed-route local bus services are inefficient and generate unsustainable ridership. Hess et al. observed that the accessibility of a transport network greatly affected the choice of transport mode, especially for older people. ${ }^{2}$ As described by Farber et al. for the city of Toronto, the accessibility of transit considerably affects its efficacy. ${ }^{3}$ Zuo et al. state that transit service can be greatly extended by improving first and last mile access to transit, and disadvantaged residents receive better and more equitable transit accessibility to jobs than others. ${ }^{4}$ Kanuri et al. state that first and last mile connectivity is an important factor in enabling greater integration and accessibility of mass transit networks to the largest number of urban residents. ${ }^{5}$ For these reasons, authorities are addressing the problem of the first and last mile connection for a public transport network as a method to improve the accessibility of the public transport service and hence its level of usage. ${ }^{6}$

Micro transit, or transit service using smaller on-demand vehicles, represents a valuable alternative for the first and last mile connection, and in recent years public transit agencies including the Santa Clara Valley Transportation Authority and the Alameda-Contra Costa Transit Authority, both in the San Francisco Bay Area, tested this model. ${ }^{7}$ For example, the AC Transit Flex pilot program, that serves the catchment area around two BART stations in Alameda County, provides an operating example of the flexible-route, on-demand last mile shuttle service contemplated in this study (except it uses manned, not automated vehicles) that improves service in low density and low demand areas while demonstrating cost neutrality and higher efficiency compared to the previous 
fixed-route service. ${ }^{8}$ A survey in 2013 performed in Santa Clara County reported that $10 \%$ of riders drive or carpool to the local public transport service. ${ }^{9}$ This share of users be a reasonable market segment to capture using new micro transit systems. In fact, through a model of existing public transit options and a hypothetical level 4 shared autonomous vehicle, Moorthy et al. explored the possibility of automated vehicles being used to solve the last mile problem, concluding that they significantly improved transit sustainability by promoting mode shifts to public transit. ${ }^{10}$

Ride hail systems are an important competitor to many public transport services, potentially replacing transit rides. ${ }^{11}$ However, Wang et al. analyzed data of Uber ride hail activity in Atlanta, highlighting that the whole ride hail fleet cannot always guarantee sufficient accessibility in terms of wait time in opposition to a well-supported public transport service. ${ }^{12}$ Chee et al. state that automated bus service competes with existing last-mile services. ${ }^{13}$ Zuo et al. state that transit accessibility to jobs can be improved with bicycles as the first-and-last mile mode, ${ }^{14}$ however, Rupi et al. (2019), ${ }^{15}$ Rupi et al. (2020), ${ }^{16}$ and Schweizer et al. ${ }^{17}$ found that cyclists try to avoid riding in the presence of buses because doing so impacts cyclist safety, speed, and waiting times. Therefore automated shuttles may offer a competitive first and last mile service.

In order to provide support for the current public transport service and not to replace it, automated shuttles should be bound within a predefined, geographically-bounded "catchment area," but it is not clear how to define these; a general methodology to determine catchment area is not yet present in literature. Biba et al. used a parcel-network method for estimating the population with walking access to bus stop locations using spatial and aspatial data (i.e. location and demographics) and the network distances from parcels to bus stop locations in order to deploy the catchment area in a 100-square-mile portion of the Dallas Area Rapid Transit (DART) system covering two Texas communities. ${ }^{18}$ Guerra et al. defined half a mile as the maximum distance from a stop or station that makes a public transport service desirable to users. ${ }^{19}$ El-Geneidy et al. declared that the $85^{\text {th }}$ percentile walking distance to bus transit service is around $524 \mathrm{~m}$ for home-based trip origins. ${ }^{20}$ Eom et al. found that about $90 \%$ of passengers traveled within $3.6 \mathrm{~km}$ from railway stations, suggesting a catchment area with a radius of less than $4 \mathrm{~km} .{ }^{21} \mathrm{AC}$ Transit recommended service zones of approximately 5-7 square miles. ${ }^{22}$ In any case, as stated by Lin et al., the catchment area can increase commensurate with changes to first and last mile service: they proved that for a dockless bike sharing system. ${ }^{23}$ However, it is important to take into account, as stated by Roy et al., that poor first and last mile performance is generally observed in more suburban locations, where poor sidewalk and bus stop infrastructure combined with the extra cost and time needed to make longer first and last mile trips using feeder buses contribute to low first and last mile quality. ${ }^{24}$ Moreover, Chee et al. declare that frequency of the primary transit routes is critical to the last-mile automated bus service usage. For this reason, the catchment areas are centered only on highfrequency bus stops in this study. 


\section{Methodology}

The following chapters describe the main challenges and benefits encountered using the BEAM software, the methodology used for determining the catchment areas of the automated shuttles, the sensitivity analysis of different parameters of the BEAM model, and the methodology used for analyzing the BEAM output files. The BEAM model was the critical software used to estimate the transportation impact of introducing automated electric shuttles to the travel network in Santa Clara County.

\subsection{BEAM Model}

The major element of the methodology involves applying the travel demand model called BEAM (Behavior, Energy, Autonomy, and Mobility), which has been under continuous development for the past two years by the Lawrence Berkeley National Laboratory, sponsored by the U.S. Department of Energy's SMART (Systems and Modeling for Accelerated Research in Transportation) Mobility Consortium. The BEAM model ${ }^{25}$ adds an important discrete choice modeling extension to MATSim, a widely used open-source software for large-scale agent-based and mesoscopic traffic simulations. BEAM also incorporates new transportation modes, most notably ride hailing, into human choice modeling, and it includes calculators for energy impacts. BEAM offers the ability to simulate a combination of several features critical for this study: defining a new vehicle type representing the automated electric shuttle; assigning the ride hail function to the shuttles; establishing geofenced areas throughout a broad area such as a county; and assigning fleets of shuttles to operate only within their specified geofenced areas.

BEAM, due to its local development origins, is pre-populated with data and calibrated for the San Francisco Bay Area. The data and model parameters are scaled to represent $10 \%$ of the population. In order for the $10 \%$ sample to generalize to the entire population, the capacity of the road network and public transit vehicle capacities are also scaled down. Therefore, even though only $10 \%$ of the population is being simulated, the agents encounter realistic levels of congestion and travel times on the roadways. Agents also encounter realistic levels of crowding on public transit vehicles. The scaling parameters were tuned and calibrated by the BEAM development team.

The BEAM model was perfectly suitable for the case study. The behavior of users in the simulation and the overall results are considered robust because the algorithms in the BEAM software, on which the simulation depends, have been validated by the BEAM working group. But, as with all beta-level software, there are a few lessons learned about the use of the software that could be useful for future users:

- BEAM requires a powerful computer. For this reason, the research team used a dedicated Linux server from Amazon Web Services (AWS) with 256 GB of random- 
access memory. The computation cost was more than 5 dollars per hour in addition to storage costs.

- The process of installing BEAM from the Git repository was quite long and required precise versions of different packages.

- BEAM does not have a graphical interface. As a result, it was not always easy to understand what was wrong when the software didn't start, how to prepare the input files, and where the output was located.

- This research project represents the first application of the BEAM model for the automated shuttle use case and in fact the BEAM development team created or updated some functions specifically to aid this study. Thus, the model is still under development: the online documentation is not always updated (see the BEAM software documentation ${ }^{26}$ ), and there are still open issues to be fixed. In fact, many proceedings required the support of the BEAM developers.

- Many of BEAM's internal processes-for example, the cost associated with each alternative during the mode choice process, waiting times, noise pollution and emissions, and so on - are not currently traceable, and the output files are limited to standard attributes.

- The output file is not intuitive, and the analysis required a significant post-processing phase.

- There are still some limitations and minor inconsistencies to be fixed. For example, simulations can currently start only at midnight. Also, if a user uses their private car for the first part of a round trip, they are unconstrained to choose another means of transport for the return trip, which is not typical and could skew the results in favor of non-automobile modes.

- The calibration of certain parameters for the Bay Area scenario changed from version to version. The parameters, and changes made to them, are often obscure and not documented. Moreover, updating the version of BEAM from the Git repository may yield a version that does not work.

- The software could clearly be used for different scenarios, but there are not enough guidelines for easily using it outside of the Bay Area, since a lot of different input files must be prepared in the right format.

Despite these challenges and drawbacks, the BEAM software produced crucial results for the case study. The main benefits encountered by using the software have been as follows. 
- The BEAM development team has been very available and generously provided support for this research. They fixed some problems that the researchers uncovered, added new functions to the model, helped with the interpretation of parameters, and suggested the best values to use. All the communications occurred in the BEAM user group, ${ }^{27}$ and the BEAM developers were very responsive. There is clearly a mutual interest concerning this study, because it represents one of the first practical applications of the BEAM model to a case study. It is important for the software developers to receive outputs resulting from the use of their software, as this aids in identifying where to improve the software and what issues should be fixed.

- BEAM is one of the few existing software programs that allows for the preparation of data for a large-scale simulation with a traffic simulator-MATSim in this case- and then provides simulation outputs. Moreover, a model defined for the whole Bay Area has been already calibrated and it is ready for use, even if it is still under development: calibration often presents a significant challenge.

- Despite its being a macroscopic model, BEAM takes into consideration a detailed transport network through OpenStreetMap (OSM), and the full public transport schedules of all the transportation agencies are pulled from their GTFS files. Moreover, the vehicle typologies are very detailed and well calibrated for the area of study, and the model considers many transportation modes (bus, ride hail, bike, car, walk) as well as multimodal combinations (walk to transit, ride hail to transit, drive to transit). This means that the model is very flexible for different typologies of macroscopic studies, even if it currently requires the support of the development team.

The total computational and storage cost using AWS was on the order of several thousands of dollars, which in addition to the final scenarios included many previous scenario runs for learning about the model behavior and sensitivity testing.

\subsection{Catchment Areas}

For the case study, the authors employed a careful process to select and size the catchment areas based on the literature review. To provide support to the bus network with automated shuttles, the research team inserted into the transportation network fleets of 20 shuttles. Each fleet was bound to provide service within a circular area with a fixed radius. The areas were placed in proximity to high-quality transit stops as a first and last mile supply for the current public transport service.

Automated shuttle operational assumptions were principally derived from the Federal Transit Administration's Strategic Transit Automation Research (STAR) Plan, which describes existing EasyMile, Local Motors, and Navya models. Based on these existing models, the theoretical automated shuttles that the team created in BEAM have SAE level 4 autonomy (can operate fully 
autonomously within specified operational domains), travel at low speeds (up to $25 \mathrm{mph}$ ), and have a capacity of 12 passengers. The literature review provided additional operational assumptions including average speed $(13 \mathrm{~km} / \mathrm{h})$, capacity (5-15 passengers/hour), typical hours of operation (6:30am-6:30pm), frequency (15-30 minutes), flexible routing, and on-demand boarding.

Both the Caltrain and the Santa Clara Valley Transportation Authority (VTA) GTFS datasets were used to identify high-quality transit stops. These datasets consist of several text files that describe the entire public transport service, including details such as hours of activities, bus routes, frequency, and stop locations.

The high-quality stops were defined as bus stops or transit stations which are visited on average by at least four buses or trains per hour, except for Caltrain, which has lesser frequency but represents major transit stations.

Once the high-quality stops were identified, the research team used ArcGIS Network Analyst to define the size of the catchment areas. The catchment areas were based on 15-minute isochrones from the high-quality stops, with a speed of $25 \mathrm{mph}$. The catchment areas were then approximated by circles, as required by BEAM. Based on this approach, the radius of each catchment area in Santa Clara County was fixed at 3,900 meters as the maximum reachable distance with these conditions. The centers of the catchment areas were placed at the center of the individual isochrone polygons.

Initially, the BEAM software did not allow ride hail vehicles to be confined to operate only within fixed areas. For this reason, the main intervention of the BEAM developers for this research was allowing certain ride hail vehicles to travel only inside a fixed round area, described by the coordinates of the center of the catchment area and its radius.

The 218 locations that were defined as the catchment areas for the automated shuttles are represented in Figure 1. With 20 vehicles in each catchment area, in all, 4,360 automated vehicles were deployed to serve these areas in the simulation. 
Figure 1. Catchment Areas for Automated Shuttles in Santa Clara County

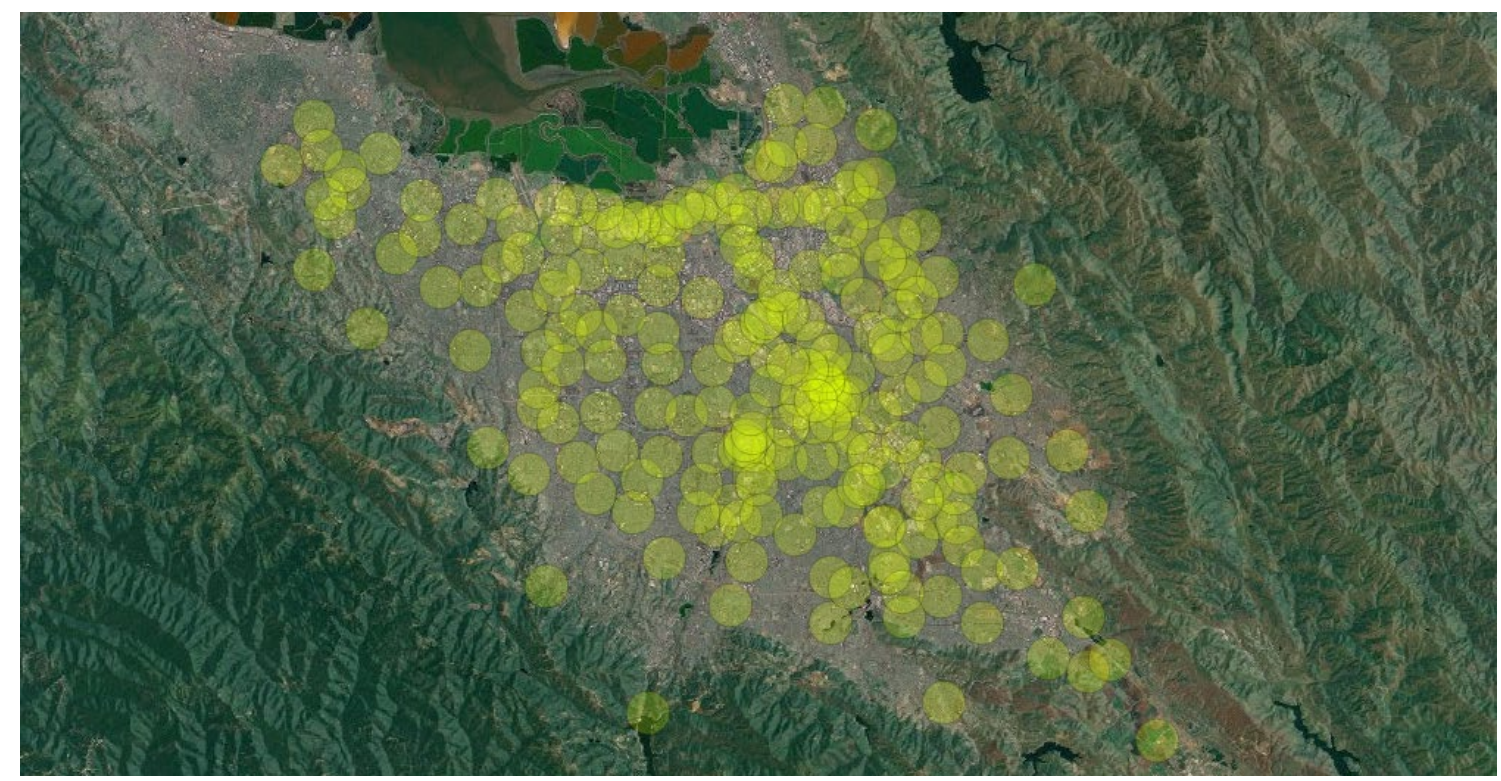

\subsection{Sensitivity Analysis and Assumed Parameters}

Before running the various scenarios, the authors performed a sensitivity analysis of different parameters of the BEAM model to understand the magnitude of impact of various input parameters and to minimize computational time: the initial position of the automated shuttles inside the catchment areas, size of the catchment areas for the automated shuttles, pricing, and number of hours simulated.

In a scenario in which the radius of the catchment areas was fixed to 3,000 meters and all of the automated vehicles started at the centers of the catchment areas, 176 trips on the automated shuttle were registered from midnight to $11 \mathrm{am}$ - the reader should keep in mind that this figure was obtained using a $10 \%$ population sample. A second scenario showed that when the initial positions of the automated vehicles are changed, trips can increase. In particular, when placing the vehicles randomly inside the relative catchment area rather than the centroid, trips increased by $50 \%$ (from 176 to 266$)$.

Increasing the size of the catchment areas led to an exponential increase in the number of trips on the automated shuttles. This is because the automated shuttles start replacing other modes of transport for point-to-point trips within the catchment areas: only 40 trips were made with a catchment area radius of 2,000 meters, 989 trips were made when the radius was increased to 6,000 meters, and 5,879 trips were made when the radius was unbounded. 
The pricing of all vehicles including ride hail vehicles is considered during the mode choice process in BEAM using utility values per mode. An increase in the utility value of the ride hail vehicles corresponds to a decrease in price. When the utility was progressively increased, this resulted in a gradual increase in the use of automated shuttles up to the capacity of the system, as expected.

However, this application of the BEAM model required the automated shuttles to share the same utility value as the other ride hail vehicles. The authors did not have the opportunity to calibrate values for the automated shuttles separate from the values previously calibrated for the other ride hail vehicles. Therefore, the authors devised a method within BEAM to differentiate the fares for the two modes by assigning travel time cost only to the automated shuttles and travel length cost only to the other ride hail vehicles, while using the same utility function. Finally, some small-scale scenarios were simulated to test the computational time required for the simulations. The authors found that the computational times related linearly with the number of iterations, number of hours of the simulation, and percentage of simulated population.

After the sensitivity analysis, the following parameters were chosen for the main scenarios.

- Simulation from midnight to $8 \mathrm{pm}$, in order to take into consideration the daily activity of users, including morning and afternoon peak hours.

- Use $10 \%$ of the real population, since the whole Bay Area model has been calibrated with this percentage of population, and using higher values could compromise the results.

- Automated shuttles with a capacity of 12 people and a maximum speed of $25 \mathrm{mph}$.

- A fixed radius of 3,900 meters for the catchment areas.

- A supply of 20 automated shuttles per catchment area, intended to represent an unconstrained supply, as the computational cost limited our ability to optimize the number of shuttles to match the estimated demand.

- A random initial position of automated vehicles inside the catchment areas in order to increase the initial accessibility of the shuttles.

- A lower average cost for automated shuttle trips compared to ride hail trips, made possible by the method described above. This reflects an assumed policy of subsidized automated shuttle fares similar to regular public transit fares and market-rate, distance-based fares for the classic ride hail services. 


\subsection{Analysis of Outputs}

Two different main scenarios were simulated: the baseline scenario of the entire San Francisco Bay Area without automated shuttles and the same scenario with the automated shuttles deployed in Santa Clara County. Each scenario required 20 iterations and 12 hours of computational time in order to reach an equilibrium of the outputs.

The main outputs provided by BEAM at the end of the simulation are stored in a table with more than 11 million event records concerning the simulation.

The main challenge in processing the output data arises due to the fact that the most useful information is categorized into four types of events that must be correlated back to each other to discern each person's whole trip across vehicles, necessary for reporting the transportation statistics shared in the Findings. The event types are: ModeChoice events, PathTraversal events, and PersonEntersVehicle and PersonExitsVehicle events.

The ModeChoice event records contain information about the overall trip of each user (with person ID, time of departure, chosen mode of transport, and total length being the most important details for this analysis), excluding the paths the user takes throughout their trip. Instead, the PathTraversal event records contain information about the paths, or portions thereof, of each vehicle (with type of vehicle and vehicle ID, trip lengths and durations, geographic coordinates of departure and arrival points, type of fuel, and energy used being the most important). For example, regarding the buses, there is a PathTraversal event between every pair of bus stops traveled between by each person on the bus. The PersonEntersVehicle and PersonExitsVehicle events relate the individual users to specific vehicles by recording the time when each person enters and leaves a vehicle. Therefore, each mode choice event contains one or more vehicle-path events and has to be merged with the other event types in order to provide complete trip information for each user and for each vehicle.

The variables that are available to match the four sets of events are the person ID, vehicle ID, departure time, and arrival time. First, we merged information about the PathTraversal events with the PersonEntersVehicle and PersonExitsVehicle events in order to associate the 'ID person' attribute to the PathTraversal events. The result of this merger was a VehicleTrips table. This table was then aggregated in order to have one unique row for each vehicle used by each person.

The aggregated table was moved to the QGIS platform in order to associate each vehicle trip to a starting and ending county. For this purpose, the team used the shape file from the California Open Data Portal, ${ }^{28}$ which describes the cartographic boundaries of the nine Bay Area counties. With a tool within QGIS that joins attributes by location, the authors associated a county with the starting and ending points of each vehicle trip. 
Finally, with the person ID and departure time attributes, the VehicleTrips table was matched with the ModeChoice events in order to obtain information about the total duration and energy of each trip, the time at which the automated shuttles were used for ride hail trips, and the starting and ending county of each trip.

At the end of the aggregation process, two main tables useful for further analysis were built.

- Trip table: each row represents a full person trip, indicating the total length, time and energy used, starting and ending county, departure time, and the transportation mode used. Multimodal trips are included in the model, and the possible modes or modal combinations available are 'Bike,' 'Car,' 'Drive and Transit (meaning a multimodal trip with driving plus transit),' 'Ride Hail,' 'Ride Hail AV ,' 'Ride Hail Pooled,' 'Ride Hail Pooled AV,' 'Ride Hail and Transit (a multimodal trip with ride hail plus transit),' 'Ride Hail AV and Transit,' 'Walk,' and 'Walk and Transit (a multimodal trip with walking and transit).' The modes with 'AV' refer to trips that include a ride hail on the automated shuttle vehicle fleet. These AV trips are distinguished from the other ride hail systems (e.g., Lyft and Uber).

- Vehicle paths table: each row represents a full vehicle trip completed by a person, indicating the vehicle type used, fuel type, total length, time and energy used, the starting and ending county, and the departure time. The vehicle types are 'AVshuttle,' 'Bike,' 'Bus,' 'Car,' 'Rail,' 'Ride Hail,' 'Tram,' and 'Walk.'

The merging process was fully realized in the $\mathrm{R}$ platform and required about 10 hours per scenario. The QGIS tool required one hour per scenario. 


\section{Findings}

In the baseline scenario, as well as the scenario with the automated shuttles, about 627,000 trips were performed by the $10 \%$ population sample of the Bay Area (see Table 1). Of these trips, $30 \%$ either started or arrived in Santa Clara County. Figure 2 shows the symmetry of the trips with respect to noon and the heat map of both the home and work activities of Santa Clara inhabitants. Moreover, $37 \%$ of the trips involving Santa Clara County started or ended in another county (see Table 2). Alameda County accounted for $48.7 \%$ of the cases and San Mateo County for $34.5 \%$. Figure 3 represents a heat map of the departure point of trips involving Santa Clara County: that is, trips inside, from, or to Santa Clara County.

Table 1. Statistics of Trips Carried Out in the Baseline Scenario

\begin{tabular}{llllll}
\hline & Bay Area & $\begin{array}{c}\text { Involving } \\
\text { SCC }\end{array}$ & $\begin{array}{c}\text { Inside } \\
\text { SCC }\end{array}$ & $\begin{array}{l}\text { From SCC to } \\
\text { Other Counties }\end{array}$ & $\begin{array}{c}\text { From Other } \\
\text { Counties to SCC }\end{array}$ \\
\hline Number of trips & 626,949 & 190,018 & 119,800 & 34,886 & 35,332 \\
Total length [km] & $17,583,796$ & $5,190,390$ & $1,951,887$ & $1,611,381$ & $1,627,122$ \\
Total time [h] & 285,661 & 70,736 & 29,567 & 20,401 & 20,768 \\
Total energy [GJ] & $39,512,627$ & $10,441,505$ & $4,179,432$ & $3,108,682$ & $3,153,391$ \\
\hline
\end{tabular}

Figure 2. Heat Map of Departures and Arrivals by Time of Day

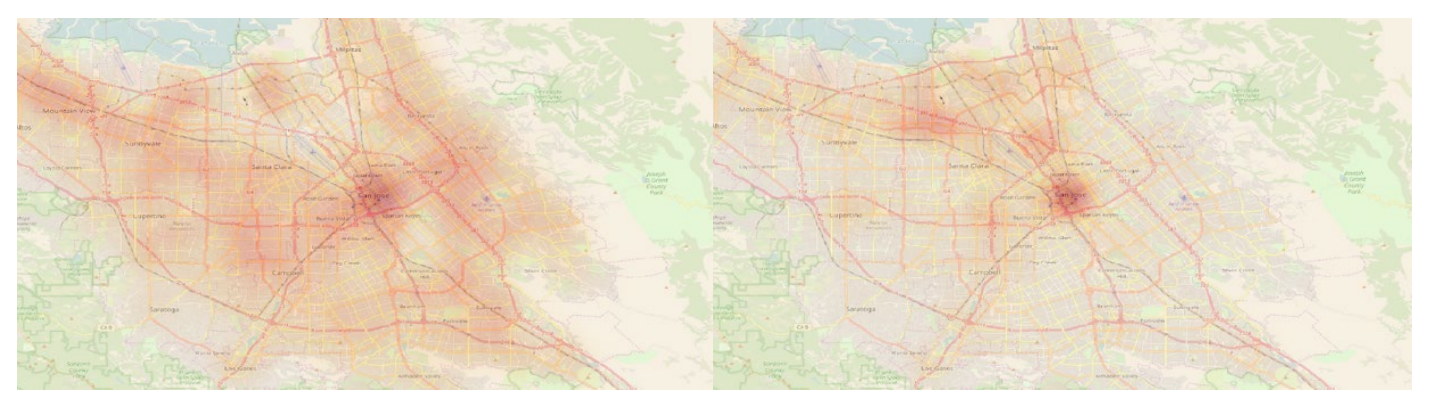

$\begin{array}{ll}\text { (a) Morning departures up to } 12 \mathrm{pm} & \text { (b) Morning arrivals up to } 12 \mathrm{pm}\end{array}$

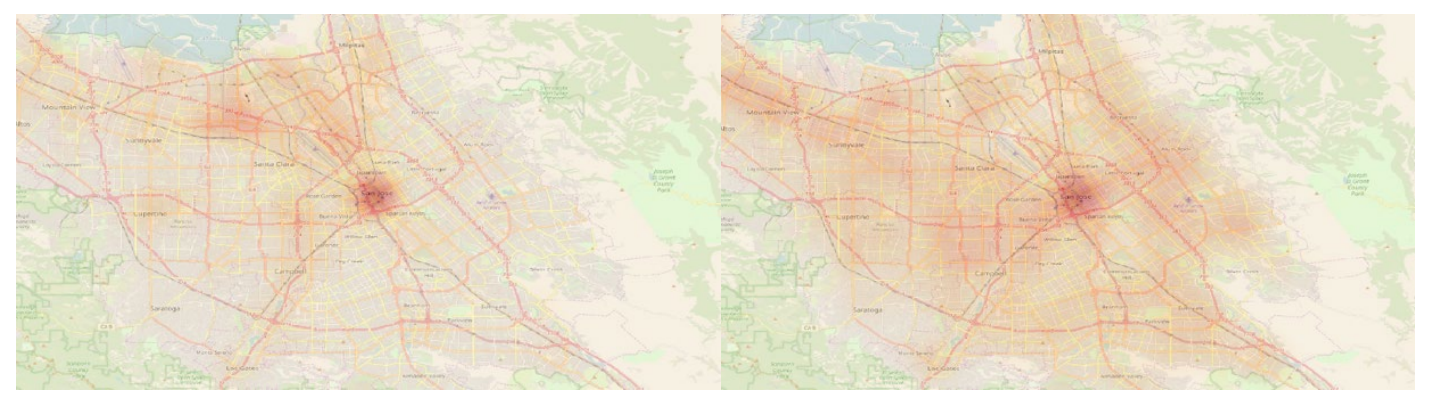

$\begin{array}{ll}\text { (c) Afternoon departures after } 12 \mathrm{pm} & \text { (d) Afternoon arrivals after } 12 \mathrm{pm}\end{array}$ 
Figure 3. Heat Map of Trips involving Santa Clara County

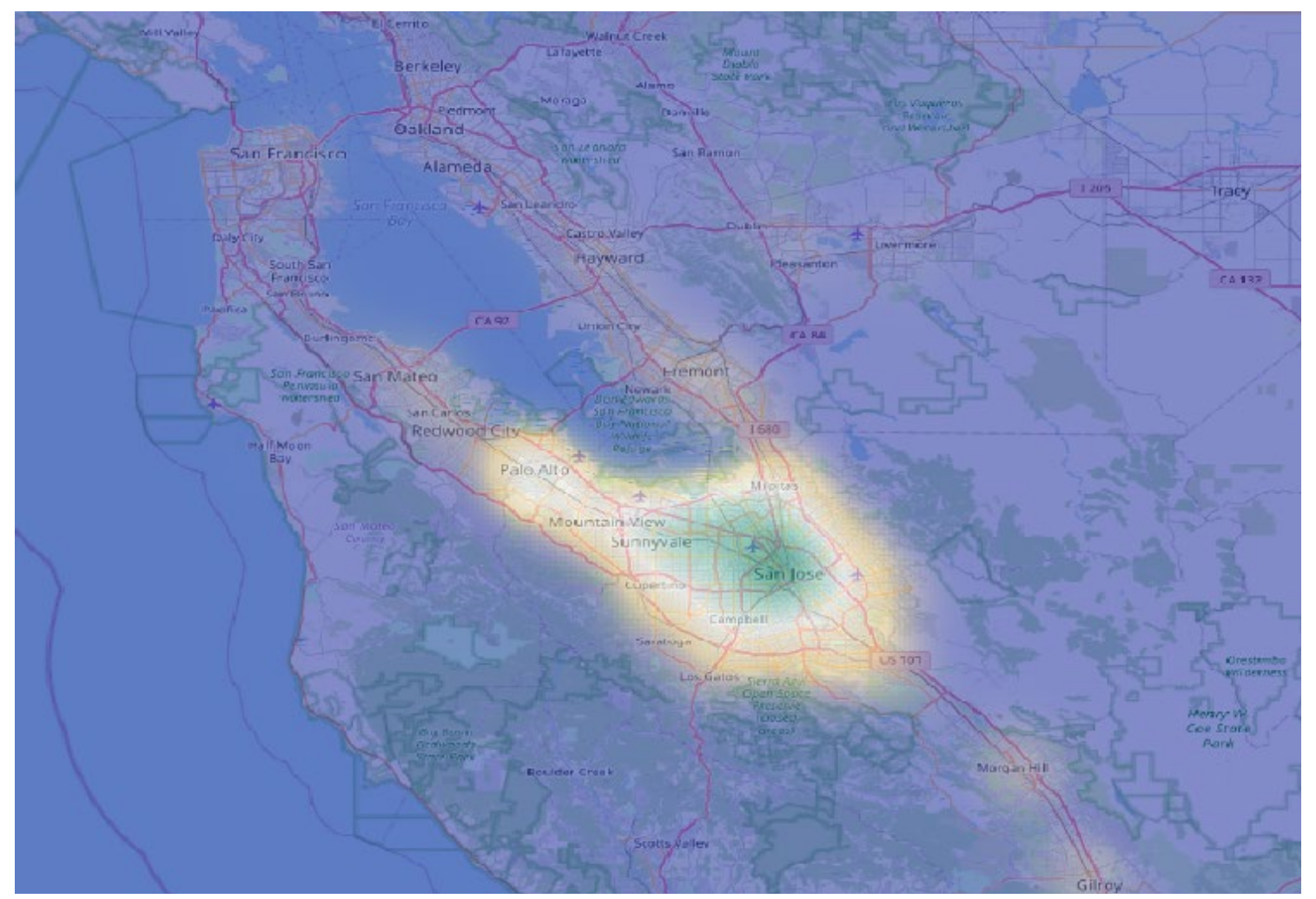

Table 2. Statistics of Trips Departing from or Arriving to Santa Clara County

\begin{tabular}{lllll}
\hline $\begin{array}{l}\text { Arrival/Departure } \\
\text { County }\end{array}$ & $\begin{array}{l}\text { From SCC to } \\
\text { Other Counties }\end{array}$ & $\begin{array}{c}\text { From Other } \\
\text { Counties to } \\
\text { SCC }\end{array}$ & $\begin{array}{c}\text { From SCC to } \\
\text { Other Counties } \\
{[\%]}\end{array}$ & $\begin{array}{c}\text { From Other } \\
\text { Counties to SCC } \\
{[\%]}\end{array}$ \\
\hline $\begin{array}{l}\text { Alameda } \\
\text { Contra Costa }\end{array}$ & 17,054 & 17,173 & 48.88 & 48.60 \\
Marin & 3,012 & 3,179 & 8.63 & 9.00 \\
Napa & 225 & 242 & 0.64 & 0.68 \\
San Francisco & 61 & 71 & 0.17 & 0.20 \\
San Mateo & 1,989 & 1,937 & 5.70 & 5.48 \\
Solano & 12,039 & 12,187 & 34.51 & 34.49 \\
Sonoma & 313 & 326 & 0.90 & 0.92 \\
\hline
\end{tabular}


Analyzing the trip mode share, in the baseline scenario the vast majority of trips were performed with private cars (see Table 3). Trips involving Santa Clara County represent a higher share of car trips with respect to the whole Bay Area, particularly for exchange trips with the other counties. Likewise, a lower share of trips involving Santa Clara County were made using sustainable means of transport: bike, transit, and walk.

The addition of the automated shuttles did not produce a meaningful change of the modal share (see Table 4). Even though a total of 1,072 95\% CI [1,008, 1,136] trips on the shuttles was registered, that theoretically corresponds to about 10,720 95\% CI [10,080, 11,360] trips by considering the whole population. These trips replaced to a small extent all the other modes, but particularly the trips inside Santa Clara County performed by the existing ride hail system, some walking trips, and car trips that were intended to reach bus stops. Trips involving the use of the automated shuttles represent $0.5 \%$ of all the trips involving Santa Clara County.

Table 3. Mode Share of Trips Involving Santa Clara County in the Baseline Scenario

\begin{tabular}{llllll}
\hline & $\begin{array}{l}\text { Bay Area } \\
{[\%]}\end{array}$ & \multicolumn{1}{c}{$\begin{array}{l}\text { Involving } \\
\text { SCC }[\%]\end{array}$} & $\begin{array}{l}\text { Inside SCC } \\
{[\%]}\end{array}$ & $\begin{array}{c}\text { From SCC } \\
{[\%]}\end{array}$ & $\begin{array}{c}\text { To SCC } \\
{[\%]}\end{array}$ \\
\hline Bike & 1.99 & 0.99 & 1.31 & 0.45 & 0.44 \\
Car & 77.10 & 88.79 & 87.06 & 91.81 & 91.68 \\
Drive and Transit & 5.79 & 2.65 & 3.49 & 1.12 & 1.31 \\
Ride Hail & 3.34 & 3.03 & 3.07 & 3.00 & 2.92 \\
Ride Hail Pooled & 0.39 & 0.26 & 0.13 & 0.48 & 0.45 \\
Ride Hail and Transit & 0.33 & 0.20 & 0.12 & 0.26 & 0.39 \\
Walk & 2.97 & 1.07 & 1.47 & 0.39 & 0.39 \\
Walk and Transit & 8.07 & 3.02 & 3.35 & 2.49 & 2.41 \\
\hline
\end{tabular}


Table 4. Mode Share of Trips Involving Santa Clara County in the Automated Shuttle Scenario

\begin{tabular}{llllll}
\hline & $\begin{array}{c}\text { Bay Area } \\
{[\%]}\end{array}$ & \multicolumn{1}{c}{$\begin{array}{l}\text { Involving } \\
\text { SCC }[\%]\end{array}$} & $\begin{array}{c}\text { Inside SCC } \\
{[\%]}\end{array}$ & $\begin{array}{c}\text { From SCC } \\
{[\%]}\end{array}$ & $\begin{array}{c}\text { To SCC } \\
{[\%]}\end{array}$ \\
\hline Bike & 2.05 & 1.09 & 1.46 & 0.45 & 0.44 \\
Car & 77.13 & 88.79 & 87.05 & 91.83 & 91.69 \\
Drive and Transit & 5.77 & 2.61 & 3.43 & 1.09 & 1.34 \\
Ride Hail & 3.09 & 2.40 & 2.19 & 2.79 & 2.72 \\
Ride Hail AV & 0.08 & 0.27 & 0.40 & 0.03 & 0.03 \\
Ride Hail Pooled & 0.46 & 0.42 & 0.40 & 0.49 & 0.45 \\
Ride Hail Pooled AV & 0.01 & 0.03 & 0.05 & 0.01 & 0.00 \\
Ride Hail and Transit & 0.30 & 0.06 & 0.03 & 0.09 & 0.12 \\
Ride Hail AV and Transit & 0.07 & 0.23 & 0.20 & 0.20 & 0.35 \\
Walk & 2.90 & 0.98 & 1.34 & 0.39 & 0.36 \\
Walk and Transit & 8.13 & 3.13 & 3.46 & 2.62 & 2.5 \\
\hline Note: AV refs to & & &
\end{tabular}

Note: AV refers to trips that involve the use of the automated shuttles.

Focusing only on the trips involving Santa Clara County that were most affected by the presence of the automated shuttles, Table 5 presents the total length, duration, and energy for each different mode in the baseline scenario, and Table 6 reports on the automated shuttle scenario. The insertion of automated shuttles did not cause a large change in these values. The total length of trips including the automated shuttles was $15,800 \mathrm{~km}$, for a cumulative trip duration of 347 hours and 32,404 GJ of energy used.

Table 5. Statistics of Trips Involving Santa Clara County in the Baseline Scenario per Transport Mode Used

\begin{tabular}{lllllllll}
\hline & & $\begin{array}{l}\text { Trips } \\
{[\%]}\end{array}$ & $\begin{array}{l}\text { Length } \\
{[\mathrm{km}]}\end{array}$ & $\begin{array}{l}\text { Length } \\
{[\%]}\end{array}$ & $\begin{array}{l}\text { Time } \\
{[\mathrm{h}]}\end{array}$ & $\begin{array}{l}\text { Time } \\
{[\%]}\end{array}$ & $\begin{array}{l}\text { Energy } \\
{[\mathrm{GJ}]}\end{array}$ & $\begin{array}{l}\text { Energy } \\
{[\%]}\end{array}$ \\
\hline Bike & 1,885 & 0.99 & 24,344 & 0.47 & 1,378 & 1.95 & 260 & 0.00 \\
Car & 168,724 & 88.79 & $4,775,980$ & 92.02 & 57,516 & 81.31 & $8,557,083$ & 81.95 \\
Drive and Transit & 5,030 & 2.65 & 69,375 & 1.34 & 1,635 & 2.31 & 360,754 & 3.46 \\
Ride Hail & 5,756 & 3.03 & 132,236 & 2.55 & 1,619 & 2.29 & 233,767 & 2.24 \\
Ride Hail Pooled & 485 & 0.26 & 24,321 & 0.47 & 275 & 0.39 & 43,138 & 0.41 \\
Ride Hail and Transit & 371 & 0.20 & 13,328 & 0.26 & 249 & 0.35 & 35,677 & 0.34 \\
Walk & 2,035 & 1.07 & 18,835 & 0.36 & 3,863 & 5.46 & 286 & 0.00 \\
Walk and Transit & 5,732 & 3.02 & 131,972 & 2.54 & 4,200 & 5.94 & $1,210,541$ & 11.59 \\
\hline
\end{tabular}


Table 6. Statistics of Trips Involving Santa Clara County in the Automated Shuttle Scenario per Transport Mode Used

\begin{tabular}{lllllllll}
\hline & Trips & $\begin{array}{l}\text { Trips } \\
{[\%]}\end{array}$ & $\begin{array}{l}\text { Length } \\
{[\mathrm{km}]}\end{array}$ & $\begin{array}{l}\text { Length } \\
{[\%]}\end{array}$ & $\begin{array}{l}\text { Time } \\
{[\mathrm{h}]}\end{array}$ & $\begin{array}{l}\text { Time } \\
{[\%]}\end{array}$ & $\begin{array}{l}\text { Energy } \\
{[\mathrm{GJ}]}\end{array}$ & $\begin{array}{l}\text { Energy } \\
{[\%]}\end{array}$ \\
\hline Bike & 2,066 & 1.09 & 25,741 & 0.50 & 1,458 & 2.05 & 275 & 0.00 \\
Car & 168,837 & 88.79 & $4,779,468$ & 92.01 & 57,787 & 81.29 & $8,564,277$ & 81.87 \\
Drive and Transit & 4,967 & 2.61 & 69,636 & 1.34 & 1,627 & 2.29 & 357,948 & 3.42 \\
Ride Hail & 4,565 & 2.40 & 119,953 & 2.31 & 1,490 & 2.10 & 211,789 & 2.02 \\
Ride Hail AV & 507 & 0.27 & 2,871 & 0.06 & 74 & 0.10 & 3,854 & 0.04 \\
Ride Hail Pooled & 806 & 0.42 & 26,165 & 0.50 & 364 & 0.51 & 46,129 & 0.44 \\
Ride Hail Pooled AV & 57 & 0.03 & 449 & 0.01 & 12 & 0.02 & 603 & 0.01 \\
Ride Hail and Transit & 108 & 0.06 & 4,254 & 0.08 & 91 & 0.13 & 13,794 & 0.13 \\
Ride Hail AV and & & & & & & & & \\
Transit & 435 & 0.23 & 12,485 & 0.24 & 261 & 0.37 & 27,948 & 0.27 \\
Walk & 1,867 & 0.98 & 17,426 & 0.34 & 3,569 & 5.02 & 243 & 0.00 \\
Walk and Transit & 5,947 & 3.13 & 136,061 & 2.62 & 4,355 & 6.13 & $1,233,661$ & 11.79 \\
\hline
\end{tabular}

Note: AV refers to trips that involve the use of the automated shuttles.

By analyzing the same attributes, this time separating out the trips by vehicle type, it is possible to observe that the use of both bus and tram increased in the automated shuttle scenario (see Table 8) with respect to the baseline scenario (see Table 7). In the automated shuttle scenario, the automated shuttles traveled for more than $6,000 \mathrm{~km}$ in 164 hours, registering an average speed of $39 \mathrm{~km} / \mathrm{h}(24 \mathrm{mph})$, close to their maximum speed of $40 \mathrm{~km} / \mathrm{h}(25 \mathrm{mph})$. The average trip distance on automated shuttles was almost $6 \mathrm{~km}$, and the average trip duration was 10 minutes. For cars, the most widely used vehicle, the average speed was $84 \mathrm{~km} / \mathrm{h}(52 \mathrm{mph})$, and the average trip duration was 20 minutes. Moreover, the multimodal trips consisting of automated shuttle plus either a bus or a tram were on average almost one hour long, suggesting that people are willing to accept a transfer between an automated shuttle and the public transport service only if the trip is long enough. 
Table 7. Statistics of Vehicles Involving Santa Clara County in the Baseline Scenario per Vehicle

\begin{tabular}{lllllll}
\hline & Trips & $\begin{array}{l}\text { Trips } \\
{[\%]}\end{array}$ & $\begin{array}{l}\text { Length } \\
{[\mathrm{km}]}\end{array}$ & $\begin{array}{l}\text { Length } \\
{[\%]}\end{array}$ & $\begin{array}{l}\text { Time } \\
{[\mathrm{h}]}\end{array}$ & $\begin{array}{l}\text { Time } \\
{[\%]}\end{array}$ \\
\hline Bike & 1,949 & 0.92 & 24,563 & 0.48 & 1,385 & 1.98 \\
Bus & 10,328 & 4.89 & 78,518 & 1.52 & 2,708 & 3.87 \\
Car & 172,956 & 81.81 & $4,806,759$ & 93.08 & 56,896 & 81.50 \\
Rail & 1,803 & 0.85 & 55,800 & 1.08 & 1,010 & 1.44 \\
Ride Hail & 6,539 & 3.09 & 159,357 & 3.09 & 1,841 & 2.63 \\
Tram & 1,856 & 0.88 & 13,296 & 0.26 & 495 & 0.71 \\
Walk & 15,979 & 7.56 & 25,601 & 0.50 & 5,488 & 7.85 \\
\hline
\end{tabular}

Table 8. Statistics of Vehicles Involving Santa Clara County in the Automated Shuttle Scenario per Vehicle

\begin{tabular}{lllllll}
\hline & Trips & $\begin{array}{l}\text { Trips } \\
{[\%]}\end{array}$ & $\begin{array}{l}\text { Length } \\
{[\mathrm{km}]}\end{array}$ & $\begin{array}{l}\text { Length } \\
{[\%]}\end{array}$ & $\begin{array}{l}\text { Time } \\
{[\mathrm{h}]}\end{array}$ & $\begin{array}{l}\text { Time } \\
{[\%]}\end{array}$ \\
\hline AV shuttle & 1,072 & 0.51 & 6,381 & 0.12 & 164 & 0.23 \\
Bike & 2,138 & 1.01 & 25,987 & 0.50 & 1,465 & 2.08 \\
Bus & 10,525 & 4.97 & 79,743 & 1.54 & 2,772 & 3.95 \\
Car & 173,012 & 81.63 & $4,809,713$ & 93.09 & 57,245 & 81.52 \\
Rail & 1,907 & 0.90 & 59,456 & 1.15 & 1,076 & 1.53 \\
Ride Hail & 5,310 & 2.51 & 146,985 & 2.84 & 1,691 & 2.4 \\
Tram & 1,978 & 0.93 & 14,052 & 0.27 & 523 & 0.74 \\
Walk & 16,008 & 7.55 & 24,575 & 0.48 & 5,289 & 7.53 \\
\hline
\end{tabular}

Funded by the U.S. Department of Energy, BEAM produces as one of its core outputs the energy use of the entire simulated transportation system, given inputs about fuel use by vehicle type. It reports energy in units of GJ, enabling comparison across fuel types; lower numbers indicate less energy used. Note the outputs do not compare elements of total lifecycle energy cost such as impact of vehicle and battery manufacturing, fossil fuel extraction and processing, fuel mix for electricity generation, etc. A journalistic discussion of recent relevant studies about electric vehicle contributions to climate change reduction is presented by Carbon Brief ${ }^{29}$ and an analysis of 59 world regions by Knobloch, et al indicates that emissions related to electric vehicles are less intensive than fossil fuel alternatives in 53 regions that represent $95 \%$ of global transport demand. ${ }^{30}$ In the United States, the U.S. Department of Energy Alternative Fuels Data Center provides a 
tool to compare well-to-wheel CO2-equivalent emissions across fuel types on a state-by-state basis, demonstrating that nationally and in all except a handful of states, emissions of all-electric vehicles are lower than those of other fuel types: plug-in hybrid, hybrid, and gasoline. ${ }^{31}$

Table 9 shows the total length, duration, and energy used for each type of fuel for the trips involving Santa Clara County. Gasoline, diesel, and biodiesel clearly dominate compared to electricity. The presence of automated shuttles replaced almost 1,000 gasoline trips $(8,300 \mathrm{~km}$ and $15,600 \mathrm{GJ}$ ) by increasing at the same time the usage of diesel vehicles due to the passengers' shift to transit. Since the transit vehicles would have operated anyway, this increase pertains to the accounting only and is not related to an increase of pollutants.

Table 9. Statistics of Trips Involving Santa Clara County in the Baseline Scenario by Fuel Type

\begin{tabular}{lllllllll}
\hline Fuel Type & Trips & $\begin{array}{l}\text { Length } \\
{[\mathrm{km}]}\end{array}$ & $\begin{array}{l}\text { Duration } \\
{[\mathrm{h}]}\end{array}$ & $\begin{array}{l}\text { Energy } \\
{[\mathrm{GJ}]}\end{array}$ & $\begin{array}{l}\text { Trips } \\
{[\%]}\end{array}$ & $\begin{array}{l}\text { Length } \\
{[\%]}\end{array}$ & $\begin{array}{l}\text { Duration } \\
{[\%]}\end{array}$ & $\begin{array}{l}\text { Energy } \\
{[\%]}\end{array}$ \\
\hline Biodiesel & 8,961 & 70,440 & 2,399 & $1,270,977$ & 4.24 & 1.36 & 3.43 & 12.30 \\
Diesel & 5,035 & 117,109 & 1,954 & 231,157 & 2.38 & 2.27 & 2.79 & 2.24 \\
Electricity & 2,191 & 22,076 & 599 & 3,878 & 1.04 & 0.43 & 0.86 & 0.04 \\
Food & 15,979 & 25,601 & 5,488 & 632 & 7.56 & 0.50 & 7.85 & 0.01 \\
Gasoline & 179,244 & $4,928,668$ & 59,474 & $8,824,334$ & 84.79 & 95.44 & 85.07 & 85.42 \\
\hline
\end{tabular}

Table 10. Statistics of Trips Involving Santa Clara County in the Automated Shuttle Scenario by Fuel Type

\begin{tabular}{lllllllll}
\hline Fuel type & Trips & $\begin{array}{l}\text { Length } \\
{[\mathrm{km}]}\end{array}$ & $\begin{array}{l}\text { Duration Energy } \\
{[\mathrm{h}]}\end{array}$ & $\begin{array}{l}\text { Trips } \\
{[\mathrm{GJ}]}\end{array}$ & $\begin{array}{l}\text { Length } \\
{[\%]}\end{array}$ & $\begin{array}{l}\text { Duration } \\
{[\%]}\end{array}$ & $\begin{array}{l}\text { Energy } \\
{[\%]}\end{array}$ \\
\hline Biodiesel & 9,142 & 71,185 & 2,446 & $1,284,419$ & 4.31 & 1.38 & 3.48 & 12.41 \\
Diesel & 5,155 & 121,358 & 2,033 & 240,929 & 2.43 & 2.35 & 2.89 & 2.33 \\
Electricity & 3,390 & 29,397 & 795 & 12,537 & 1.60 & 0.57 & 1.13 & 0.12 \\
Food & 16,008 & 24,575 & 5,289 & 597 & 7.55 & 0.48 & 7.53 & 0.01 \\
Gasoline & 178,255 & $4,920,378$ & 59,662 & $8,808,704$ & 84.10 & 95.23 & 84.96 & 85.13 \\
\hline
\end{tabular}

Figure 4 represents the distribution of departures of the automated shuttles together with cars, other ride hails, and public transport services. It is evident that the automated shuttle service was used particularly during the night hours. 
In order to analyze the spatial distribution of the starting points of trips on the automated shuttles, Figure 5 represents the starting points superimposed on an OpenStreetMap (OSM) map of Santa Clara County. The figure shows that most trips are concentrated in downtown San José, but they are also distributed across the whole county.

Regarding vehicle occupancy, there were only a few pooled trips on the automated shuttle. One limitation of BEAM is that it currently doesn't allow agents to choose a trip consisting of a pooled ride hail leg followed by a transit leg. (Agents can choose a trip consisting of a single-passenger ride hail leg connecting to a transit leg.) If pooled trips to transit were allowed, we might see an increase in pooled trips and a decrease in single-passenger trips. Allowing pooled trips to transit would also effectively increase the capacity of the AV system without adding any vehicles. However, we don't believe the AV capacity was a limiting factor in the simulation because of the large number of AVs deployed.

Figure 4. Relative Frequency Distribution of Departure Time of Automated Shuttles during the Day, Compared with the Usage of Cars, Other Ride Hails, and Public Transport Service

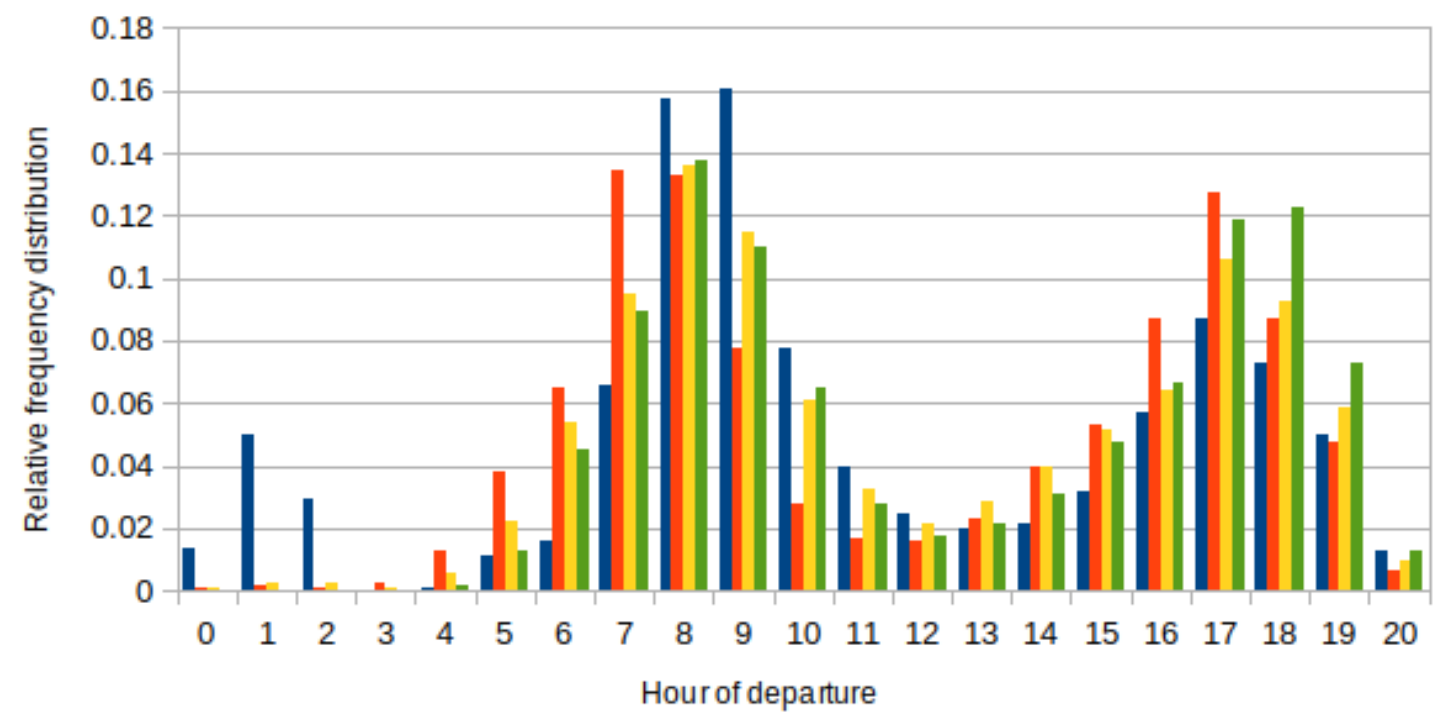

- Automated shuttles a Car $₫$ Ridehail $\square$ Public Transport 
Figure 5. Spatial Distribution of Departures of Automated Shuttles' Trips in Santa Clara County When Using a 10\% Population Sample

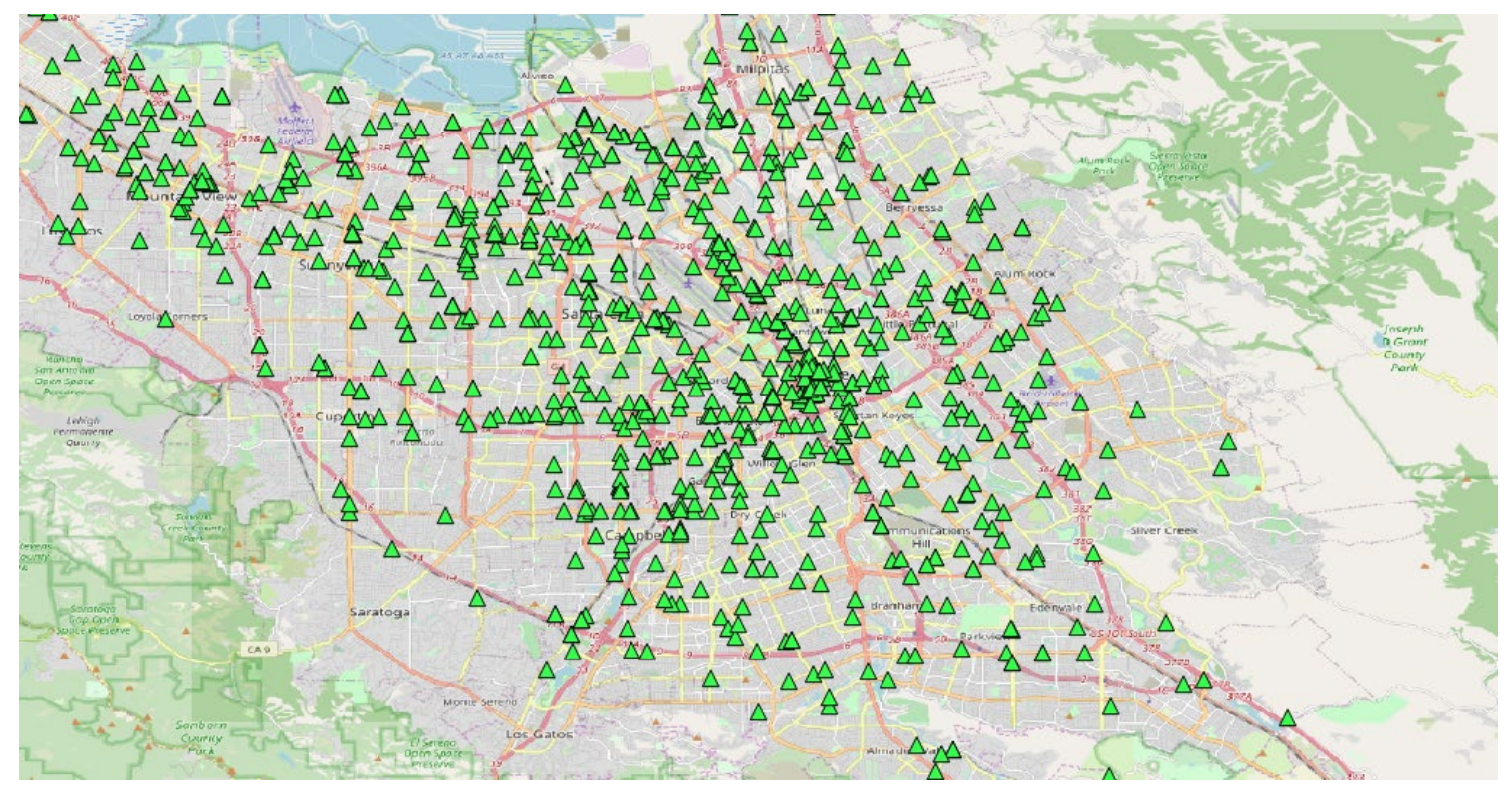




\section{Conclusion}

The main goal of the present study was to evaluate the impacts of a fleet of automated shuttles in Santa Clara County providing first and last mile connections to the current public transportation system. The secondary goal was to use and test the BEAM software developed at Lawrence Berkeley National Laboratory.

BEAM was selected for use in this study because of its ability to simulate the combination of several critical features: defining a new vehicle type approximating the automated electric shuttle form factor and performance; assigning ride hail functions to the new shuttles; establishing geofenced areas throughout a broad area such as a county; assigning the shuttles to specific geofenced areas. BEAM demonstrated the capability to simulate the proposed automated shuttle service, and this report describes the lessons learned from using the model as well as suggestions for future users.

Regarding the Santa Clara County scenario, the model suggests that automated shuttles would be chosen by some users for various trip types including first and last mile connections to transit. The model estimated 1,100 trips in one simulated day carried out by a $10 \%$ population sample. The trips were distributed across the county, though they were particularly concentrated in downtown San José. The automated shuttles were confined within circular catchment areas centered on major bus stops and transit stations. The average trip length was $6 \mathrm{~km}$, with an average speed of $35 \mathrm{~km} / \mathrm{h}$, due to the low assumed maximum operating speed of $40 \mathrm{~km} / \mathrm{h}$.

Users of the automated shuttles shifted mainly from gas trips-principally from other ride hail vehicles directed to bus stops-but also walking trips. The usage of public transport services increased with the presence of the automated shuttles. The choice to use an automated shuttle plus either a bus or tram was found to happen most frequently for trip durations of approximately one hour. Moreover, considering the higher usage of the automated shuttles during the night hoursmainly between midnight and 2am-as well as the increase of the usage of public transport and replacements of walking trips, it's possible that automated shuttles serve to increase the accessibility to users for public transport and offer a good solution in certain contexts.

Some problems encountered in this study and possible solutions are discussed below. Future research could provide further insight into the potential use of the automated shuttles for connectivity.

- The BEAM model currently does not include an option for users to ride a pooled ride hail vehicle to connect to transit; instead only allowing single-passenger ride hail trips. The addition of this option could be crucial for the use of the automated shuttles, since they offer a capacity of 12 people. 
- The center of each catchment area does not exactly align with the coordinates of the high-quality transit stops. The centers were placed to best approximate the 15 -minute isochrones around the high-quality transit stops. This might have decreased the efficiency of the connections between the automated shuttles and the current public transport network.

- The coefficients of the utility function related to the automated shuttles could be adjusted to be different with respect to the already-calibrated coefficients associated with the standard ride hail system. Treating the automated shuttles as a separate mode would allow the more flexible use of coefficients to test modal assumptions and policy interventions of the shuttles, such as different pricing schemes, separately from the standard ride hail system.

- The use of a non-fixed radius could improve accuracy, based on the individual isochrones and tailored to the attractiveness of specific transit stops/stations.

- BEAM could impose a constraint requiring that both legs of a round trips should use the same modes. For example, if a user drives their car to a bus stop, they should arrive at this bus stop and reuse their car on the return trip. Conversely, if a user drives their car to their end destination, they should also reuse their car on the return trip. Imposing this constraint would make the individual agent-level modal choices more realistic.

- The number of automated shuttles supplied can be weighted based on sociodemographic attributes of catchment areas around high-quality stops, or otherwise optimized to match demand, which would give a better indication of fleet size requirements and cost implications.

- The model considers just $10 \%$ of the population. In future it will be possible to consider the whole population, since recently the entire Bay Area population has been made available for use with the model, but some interventions that require the BEAM developers' support are needed to change the output files. Considering the whole population could allow a better estimate of pooled trips as well as reveal meaningful correlations between trip-making and land use characteristics such as density. Currently, there are too few simulated automated shuttle trips to draw a conclusion, and the sampled population changes between model runs. Clearly, simulating the whole population will require much greater computational resources for both the simulation and the output analysis.

- The model is calibrated to the relatively recent year 2015, but even since then, dramatic changes have occurred in observed travel behavior. These changes have included 
exponential increases in ride hail activity accompanied by modest declines in public transit use, the sudden introduction of completely new shared micro mobility services in many cities across the Bay Area, and most recently, in 2020, profound disruption of various transportation modes (particularly public transit) due to the COVID-19 pandemic. Calibration with sufficient data is a challenge for any model, and it is particularly important for the purpose of estimating new modes and scenarios.

The main benefit of this work has been demonstrating that the BEAM model, despite its beta status, limitations, and difficulty to use, allowed for the analysis of a large-scale scenario in a quite high level of detail. As the BEAM model continues to be developed, it will become more robust and capable in the future. The BEAM developers have been very open to inserting new tools, parameters, and functions to adapt BEAM to this case study. Moreover, the BEAM model is very flexible for analyzing different interventions on the baseline scenario and could clearly be adapted to a multitude of different studies. 


\section{Abbreviations and Acronyms}

$\begin{array}{ll}\text { AV } & \text { Automated Vehicle } \\ \text { AWS } & \text { Amazon Web Services } \\ \text { BEAM } & \text { The Modeling Framework for Behavior, Energy, Autonomy, and Mobility } \\ \text { CI } & \text { Confidence Interval } \\ \text { GIS } & \text { Geographic Information System } \\ \text { MATSim } & \text { Multi-Agent Transport Simulation } \\ \text { OSM } & \text { OpenStreetMap } \\ \text { SCC } & \text { Santa Clara County } \\ \text { SMART } & \text { Systems and Modeling for Accelerated Research in Transportation } \\ \text { STAR } & \text { Strategic Transit Automation Research } \\ \text { VTA } & \text { Santa Clara Valley Transportation Authority }\end{array}$




\section{Endnotes}

${ }^{1}$ Sheppard, C., and R. Waraich, A. Campbell, A. Pozdnukhov, A. R. Gopal. "Modeling Plug-in Electric Vehicle Charging Demand with BEAM.” Lawrence Berkeley National Laboratory, May 2017, LBNL-2001018.

${ }^{2}$ Hess, Daniel Baldwin. "Access to Public Transit and Its Influence on Ridership for Older Adults in Two U.S. Cities." Journal of Transport and Land Use 2, no. 1 (2009): 3-27.

${ }^{3}$ Farber, Steven, and Maria Grandez. "Transit Accessibility, Land Development and Socioeconomic Priority: A Typology of Planned Station Catchment Areas in the Greater Toronto and Hamilton Area." Journal of Transport and Land Use 10, no. 1 (2017): 879-902.

${ }^{4}$ Zuo, T., H. Wei and N. Chen. "Promote transit via hardening first-and-last-mile accessibility: Learned from modeling commuters' transit use." Transportation Research Part D: Transport and Environment 86 (2020): 102446. DOI: https://doi.org/10.1016/j.trd.2020.102446

${ }^{5}$ Kanuri, C., K. Venkat, S. Maiti and P. Mulukutla "Leveraging Innovation for Last Mile Connectivity to Mass Transit" Transportation Research Procedia 41 (2019): 655-669. DOI: https://doi.org/10.1016/j.trpro.2019.09.114

${ }^{6}$ Santa Clara Valley Transportation Authority. "Transit Service Guidelines." San José, April 2018. URL: http://www.vta.org/proj-ects-and-programs/programs/tran

${ }^{7}$ Eno Center for Transportation. "UpRouted: Exploring Microtransit in the United States." Washington D.C., January 2018.

${ }^{8}$ Viii AC Transit. AC Transit Flex Pilot Program. Oakland, CA, 2017.

${ }^{9}$ Corey, Canapary, \& Galanis. VTA On-Board Survey 2013: Management Summary Report. Management Summary Report, San José: Santa Clara Valley Transit Authority, 2014, 1-76.

${ }^{10}$ Moorthy, A., et al. "Shared Autonomous Vehicles as a Sustainable Solution to the Last Mile Problem: A Case Study of Ann Arbor-Detroit Area," SAE International Journal of Passenger CarsElectronic and Electrical Systems 10, no. 2 (2017).

${ }^{11}$ International Transport Forum. Shared Mobility Simulations for Helsinki. Paris, France: Organisation for Economic Co-operation and Development, 2017.

${ }^{12}$ Wang, Mingshu, and Lan Mu. "Spatial Disparities of Uber Accessibility: An Exploratory Analysis in Atlanta, USA.” Computers, Environment and Urban Systems 67 (2018): 169-175.

${ }^{13}$ Chee, Susilo and Wong. "Determinants of Intention-to-Use First-/Last-Mile Automated Bus Service." Transportation Research Part A: Policy and Practice 139 (2020): 350-375. DOI: https://doi.org/10.1016/j.tra.2020.06.001 
${ }^{14}$ Zuo, Wei, Chen and Zhang, "First-and-Last Mile Solution via Bicycling to Improving Transit Accessibility and Advancing Transportation Equity." Cities 99 (2020): 102614. DOI: https://doi.org/10.1016/j.cities.2020.102614

${ }^{15}$ Rupi, Poliziani and Schweizer "Data-Driven Bicycle Network Analysis Based on Traditional Counting Methods and GPS Traces from Smartphone." ISPRS International Journal of GeoInformation 8 (2019): 322. DOI: https://doi.org/10.3390/ijgi8080322

${ }^{16}$ Rupi, Schweizer and Poliziani "Analysing the Dynamic Performances of a Bicycle Network with a Temporal Analysis of GPS Traces." Case Studies on Transport Policy 8, no. 3 (2020): 770777. DOI: https://doi.org/10.1016/j.cstp.2020.05.007

${ }^{17}$ Schweizer, Rupi and Poliziani "Estimation of link-cost function for cyclists based on stochastic optimization and GPS traces" ITE Intelligent Transport Systems, in press.

${ }^{18}$ Biba, S., Curtin, K. M., and Manca, G. "Who can Access Transit? Reviewing Methods for Determining Population Access to Bus Transit." Cityscape 16, no. 2 (2014): 193-203.

${ }^{19}$ Guerra, Erick, Robert Cervero, and Daniel Tischler. "Half-Mile Circle." Transportation Research Record: Journal of the Transportation Research Board 2276, no.1 (2012): 101-109.

${ }^{20}$ El-Geneidy, Ahmed, Michael Grimsrud, Rania Wasfi, Paul Tétreault, and Julien SurprenantLegault. "New Evidence on Walking Distances to Transit Stops: Identifying Redundancies and Gaps Using Variable Service Areas.” Transportation 41, no. 1 (2013): 193-210.

${ }^{21}$ Eom, Choi, Park and Heo "Exploring the catchment area of an urban railway station by using transit card data: Case study in Seoul” Cities 95 (2019): 102364 DOI:

https://doi.org/10.1016/j.cities.2019.05.033

${ }^{22}$ AC Transit. AC Transit Flex Pilot Program. Oakland, CA, 2017.

${ }^{23}$ Lin, Zhang, Zhu, Meng, "The Analysis of Catchment Areas of Metro Stations Using Trajectory Data Generated by Dockless Shared Bikes" Sustainable Cities and Society 49 (2019): 101598. DOI: https://doi.org/10.1016/j.scs.2019.101598

${ }^{24}$ Roy and Basu, "Selection of intervention areas for improving travel condition of walk-accessed bus users with a focus on their accessibility: An experience in Bhubaneswar" Transport Policy 96 (2020): 29-39. DOI: https://doi.org/10.1016/j.tranpol.2020.06.004

${ }^{25} \mathrm{BEAM}$ web site, http://beam.lbl.gov.

${ }^{26}$ Documentation of the BEAM software, https://beam.readthedocs.io/en/latest/users.html.

${ }^{27}$ BEAM User Group, https://groups.google.com/forum/\#!forum/beam-model-users.

${ }^{28}$ California Open Data Portal, https://gis.data.ca.gov. 
${ }^{29}$ Carbon Brief. Factcheck: How electric vehicles help to tackle climate change. United Kingdom, June 2020. https://www.carbonbrief.org/factcheck-how-electric-vehicles-help-totackle-climate-change

${ }^{30}$ F. Knobloch, S. Hanssen, A. Lam, et al. Net Emission Reductions from Electric Cars and Heat Pumps in 59 World Regions Over Time. Nat Sustain 3, 437-447 (2020).

https://doi.org/10.1038/s41893-020-0488-7

${ }^{31}$ U.S. Department of Energy, Energy Efficiency \& Renewable Energy Program, Alternative Fuels Data Center. Emissions from Hybrid and Plug-In Electric Vehicles. September 2020. https://afdc.energy.gov/vehicles/electric_emissions.html 


\section{Bibliography}

AC Transit. AC Transit Flex Pilot Program. Oakland, CA, 2017. Retrieved May 5, 2020, from http://www.actransit.org/flex/.

Alemi, F., G. Circella, S. Handy, and P. Mokhtarian. "What Influences Travelers to Use Uber? Exploring the Factors Affecting the Adoption of On-Demand Ride Services in California." Travel Behaviour and Society 13 (2018). DOI: https://doi.org/10.1016/j.tbs.2018.06.002

BEAM documentation. Retrieved May 5, 2020, from https://beam.readthedocs.io/en/latest/users.html.

BEAM User Group. Retrieved May 5, 2020, from https://groups.google.com/forum/\#!forum/beam-model-users.

BEAM web site. Retrieved May 5, 2020, from http://beam.lbl.gov.

Benenson, I., K. Martens, Y. Rofé, and A. Kwartler. "Public Transport versus Private Car GISBased Estimation of Accessibility Applied to the Tel Aviv Metropolitan Area." The Annals of Regional Science 47, no. 3 (2011): 499-515. DOI: http://dx.doi.org/10.1007/s00168-010-0392-6

Bergmann, F. M., S. M. Wagner and M. Winkenbach, “Integrating First-Mile Pickup and Last-Mile Delivery on Shared Vehicle Routes for Efficient Urban e-commerce Distribution." Transportation Research Part B: Methodological 131 (2020): 26-62. DOI: https://doi.org/10.1016/j.trb.2019.09.013

Biba, S., K. M. Curtin, and G. Manca. "Who can Access Transit? Reviewing Methods for Determining Population Access to Bus Transit." Cityscape 16, no. 2 (2014): 193-203. DOI: https://doi.org/10.1080/13658810802646679

Blumenberg, E., G. Pierce, and M. Smart. "Transportation Access, Residential Location, and Economic Opportunity: Evidence from Two Housing Voucher Experiments.” Cityscape 17, no. 2 (2015): 89-111. Retrieved May 5, 2020, from www.jstor.org/stable/26326941

California Open Data Portal. Retrieved May 5, 2020, from https://gis.data.ca.gov.

Chee, P. N. E., Y. O. Susilo and Y. D. Wong. "Determinants of Intention-to-Use First-/LastMile Automated Bus Service." Transportation Research Part A: Policy and Practice 139 (2020): 350-375. DOI: https://doi.org/10.1016/j.tra.2020.06.001 
Corey, Canapary, Galanis. VTA On-Board Survey (2014): Management Summary Report, San José: Santa Clara Valley Transit Authority, 1-76. Retrieved May 5, 2020, from http://openbook.sfgov.org/webreports/details3.aspx?id=2705.

El-Geneidy, Ahmed, Michael Grimsrud, Rania Wasfi, Paul Tétreault, and Julien SurprenantLegault. "New Evidence on Walking Distances to Transit Stops: Identifying Redundancies and Gaps Using Variable Service Areas.” Transportation 41 (2014): 193210. DOI: https://doi.org/10.1007/s11116-013-9508-z

Eno Center for Transportation. "UpRouted: Exploring Microtransit in the United States." Washington, D.C., 2018. Retrieved May 5, 2020, from https://www.enotrans.org/enoresources/uprouted-exploring-microtransit-united-states/.

Eom, J. K., J. Choi and M. S. Park, T. Y. Heo "Exploring the catchment area of an urban railway station by using transit card data: Case study in Seoul” Cities 95 (2019): 102364 DOI: https://doi.org/10.1016/j.cities.2019.05.033Guerra, E., R. Cervero, and D. Tischler. "Half-Mile Circle." Transportation Research Record: Journal of the Transportation Research Board 2276, no. 1 (2012): 101-109. DOI: https://doi.org/10.3141/2276-12

Hess, Daniel Baldwin. "Access to Public Transit and Its Influence on Ridership for Older Adults in Two U.S. Cities." Journal of Transport and Land Use 2, no. 1 (2009): 3-27. DOI: https://doi.org/10.5198/jtlu.v2i1.11

International Transport Forum. "Shared Mobility Simulations for Helsinki." Paris, France: Organisation for Economic Co-operation and Development, 2017. Retrieved May 5, 2020, from https://www.itf-oecd.org/sites/default/files/docs/shared-mobilitysimulations-helsinki.pdf.

Kanuri, C., K. Venkat, S. Maiti and P. Mulukutla "Leveraging Innovation for Last Mile Connectivity to Mass Transit” Transportation Research Procedia 41 (2019): 655-669. DOI: https://doi.org/10.1016/j.trpro.2019.09.114

Lin, D., Y. Zhang, R. Zhu, L. Meng, "The Analysis of Catchment Areas of Metro Stations Using Trajectory Data Generated by Dockless Shared Bikes" Sustainable Cities and Society 49 (2019): 101598. DOI: https://doi.org/10.1016/j.scs.2019.101598Mingshu, W., and L. Mu. "Spatial Disparities of Uber Accessibility: An Exploratory Analysis in Atlanta, USA.” Computers, Environment and Urban Systems 67 (2018): 169-175. DOI: https://doi.org/10.1016/j.compenvurbsys.2017.09.003

Moira, Z., D. Massey, Y. Shiftan, J. Levine, and M. J. Arquero. "Overcoming the Last-Mile Problem with Transportation and Land-Use Improvements: An Agent-Based 
Approach.” International Journal of Transportation 4, no. 1 (2016): 1-26. DOI: 10.14257/ijt.2016.4.1.01

Moorthy, A., R. De Kleine, G. Keoleian, J. Good, and G. M. Lewis. "Shared Autonomous Vehicles as a Sustainable Solution to the Last Mile Problem: A Case Study of Ann Arbor-Detroit Area." SAE International Journal of Passenger Cars-Electronic and Electrical Systems 10, no. 2 (2017). DOI: https://doi.org/10.4271/201701-1276

Noland, R. B., and S. DiPetrillo. "Transit-Oriented Development and the Frequency of Modal Use." Journal of Transport and Land Use 8, no. 2 (2015): 21-44. DOI: https://doi.org/10.5198/jtlu.2015.517

Ouassim, M., P. Bonnel, and L. Bouzouina. "Transit Accessibility: A New Definition of Transit Connectors." Transportation Research Part A: Policy and Practice 113 (2018): 88-100. DOI: https://doi.org/10.1016/j.tra.2018.03.028

Roy, S. and D. Basu, "Selection of intervention areas for improving travel condition of walkaccessed bus users with a focus on their accessibility: An experience in Bhubaneswar" Transport Policy 96 (2020): 29-39. DOI: https://doi.org/10.1016/j.tranpol.2020.06.004

Rupi, F., C. Poliziani and J. Schweizer "Data-Driven Bicycle Network Analysis Based on Traditional Counting Methods and GPS Traces from Smartphone." ISPRS International Journal of Geo-Information, 8 (2019): 322. DOI:

https://doi.org/10.3390/ijgi8080322https://doi.org/10.3390/ijgi8080322https://doi.org/1 0.3390/ijgi8080322

Rupi, F., J. Schweizer and C. Poliziani "Analysing the Dynamic Performances of a Bicycle Network with a Temporal Analysis of GPS Traces." Case Studies on Transport Policy 8, no. 3 (2020): 770-777. DOI: https://doi.org/10.1016/j.cstp.2020.05.007Sabyasachee, M., T. F. Welch, P. M. Torrens, C. Fu, H. Zhu, and E. Knaap. "A Tool for Measuring and Visualizing Connectivity of Transit Stop, Route and Transfer Center in a Multimodal Transportation Network." Public Transport (2015): 77-99. DOI: https://doi.org/10.1007/s12469-014-0091-2

Salonen, A. O. "Passenger's Subjective Traffic Safety, In-Vehicle Security and Emergency Management in the Driverless Shuttle Bus in Finland." Transport Policy 61 (2018): 106110. DOI: https://doi.org/10.1016/j.tranpol.2017.10.011

Santa Clara Valley Transportation Authority. “Transit Service Guidelines.” San José, 2018. Retrieved May 5, 2020, from http://www.vta.org/proj-ects-and-programs/programs/tran. 
Schweizer, J., F. Rupi and C. Poliziani "Estimation of link-cost function for cyclists based on stochastic optimization and GPS traces" ITE Intelligent Transport Systems, in press.

Sheppard, C., and R. Waraich, A. Campbell, A. Pozdnukhov, A. R. Gopal. "Modeling Plug-in Electric Vehicle Charging Demand with BEAM.” Lawrence Berkeley National Laboratory, May 2017, LBNL-2001018.

Steven, F., and M. Grandez. "Transit Accessibility, Land Development and Socioeconomic Priority: A Typology of Planned Station Catchment Areas in the Greater Toronto and Hamilton Area." Journal of Transport and Land Use 10, no. 1 (2017): 879-902. DOI: https://doi.org/10.5198/jtlu.2017.980

Venter, C. J. "Measuring the Quality of the First/Last Mile Connection to Public Transport." Research in Transportation Economics (2020): 100949. DOI: https://doi.org/10.1016/j.retrec.2020.100949

Yang, C., and J. Wang. "The Key Contributing Factors of Customized Shuttle Bus in Rush Hour: A Case Study in Harbin City." Procedia Engineering 137 (2016): 478-486. DOI: https://doi.org/10.1016/j.proeng.2016.01.283

Zuo, T., H. Wei and N. Chen. "Promote transit via hardening first-and-last-mile accessibility: Learned from modeling commuters' transit use.” Transportation Research Part D: Transport and Environment 86 (2020): 102446. DOI: https://doi.org/10.1016/j.trd.2020.102446

Zuo, T., H. Wei, N. Chen and C. Zhang, "First-and-Last Mile Solution via Bicycling to Improving Transit Accessibility and Advancing Transportation Equity." Cities 99 (2020): 102614. DOI: https://doi.org/10.1016/j.cities.2020.102614 


\section{About the Authors}

\section{Gary Hsueh}

Gary is the Director of Mobility Programs at CHS Consulting Group and a Mineta Transportation Institute Consulting Associate. He develops and implements transportation technology demonstration projects and establishes industry-civic-academic partnerships to benefit society. Gary recently supported the Santa Clara VTA Accessible Automated Vehicle demonstration project, and also concluded the role of Principal Investigator for the FTA-funded Palo Alto Mobility on Demand Demonstration Project. Previously, Gary worked for nearly 13 years as a transportation planner with Arup, and he is a certified planner (AICP). Gary holds a BA in Geography from UC Berkeley and an MS in Transportation Management through the Mineta Transportation Institute at San José State University.

\section{David Czerwinski}

David is an Associate Professor in the Department of Marketing and Business Analytics at San José State University and a Mineta Transportation Institute Research Associate. His research involves the application of techniques from operations research and statistics to problems in the private and public sectors. He previously worked in the Planning Department of the Chicago Transit Authority and as a Senior Associate at Transportation Management \& Design. He holds a BS in Mathematical and Computational Science from Stanford University and a $\mathrm{PhD}$ in Operations Research from the Massachusetts Institute of Technology.

\section{Cristian Poliziani}

Cristian is a PhD student at the Department DICAM of the University of Bologna, Italy in the field of Transport Engineering. His research activity focuses on the development of large-scale traffic micro-simulation models and on performing deep analysis of big data related to GPS traces of cyclists, pedestrians, and public transport users in order to estimate the impacts and the performance of sustainable means of transport. Cristian currently is a Visiting Scholar at San José State University in collaboration with the nonprofit organization Prospect Silicon Valley.

\section{Terris Becker}

Terris Becker is a statistician with an MS in Statistics from San José State University and is currently working for a finance company in Vancouver, WA as a data analyst. His areas of expertise are statistical modeling, experimental design and analysis, and stochastic processes.

\section{Alexandre Hughes}

Alexandre is a practicing planner working on citywide planning and public policy. He graduated from San José State University with his Master's Degree in Urban and Regional Planning in 2019. 
His Master's project focused on the intersection of university policy and the use of electric scootershare devices using GIS analytics.

\section{Peter Chen}

Peter Chen, $\mathrm{PhD}$, is a Senior Transportation Planner at Santa Clara Valley Transportation Authority. He obtained his BS and MS from National Taiwan University, his PhD from University of Maryland, College Park, and an MBA from Santa Clara University. Peter works across several diverse fields including public transportation planning and operations, traffic simulation, and travel demand modeling, especially the recent development of activity-based models and their application to public transportation. He is a member of the Bus Transit Systems Committee and the Public Transportation Planning and Development Committee of the Transportation Research Board as well as being a handling editor of Transportation Research Record Board.

\section{Melissa Benn}

Melissa is a Program Associate at Prospect Silicon Valley. She earned her BA in Environmental Studies from the University of California, Santa Cruz in 2016, specializing in sustainable architecture and ecological conservation. She joined Prospect Silicon Valley in January 2018 as a fellow through Climate Corps Bay Area and has since transitioned to engage in many transportation initiatives including the Palo Alto Mobility on Demand Demonstration Project, the Santa Clara VTA Vehicle-to-Grid Integration Project, Transit Technology and Connected Vehicle Working Groups, and the VTA Accessible Automated Vehicle demonstration project. 


\section{Hon. Norman Y. Mineta}

\section{MTI BOARD OF TRUSTEES}

Founder, Honorable Norman

Mineta*

Secretary (ret.),

US Department of Transportation

Chair,

Abbas Mohaddes

President \& COO

Econolite Group Inc.

Vice Chair,

Will Kempton

Executive Director

Sacramento Transportation Authority

Executive Director,

Karen Philbrick, PhD*

Mineta Transportation Institute

San José State University

Winsome Bowen

Chief Regional Transportation

Strategy

Facebook

David Castagnetti

Co-Founder

Mehlman Castagnetti

Rosen \&Thomas

\section{Maria Cino}

Vice President

America \& U.S. Government

Relations Hewlett-Packard

Enterprise

\author{
Grace Crunican** \\ Owner \\ Crunican LLC
}

Donna DeMartino

Managing Director

Los Angeles-San Diego-San Luis

Obispo Rail Corridor Agency

Nuria Fernandez**

General Manager \& CEO

Santa Clara Valley Transportation

Authority (VTA)

\section{John Flaherty}

Senior Fellow

Silicon Valley American

Leadership Form

William Flynn *

President \& CEO

Amtrak

Rose Guilbault

Board Member

Peninsula Corridor

Joint Powers Board

Ian Jefferies*

President \& CEO

Association of American

Railroads
Diane Woodend Jones

Principal \& Chair of Board

Lea + Elliott, Inc.

David S. Kim*

Secretary

California State Transportation

Agency (CALSTA)

Therese McMillan

Executive Director

Metropolitan Transportation

Commission (MTC)

Bradley Mims

President \& CEO

Conference of Minority

Transportation Officials

(COMTO)

Jeff Morales

Managing Principal

InfraStrategies, LLC

Dan Moshavi, PhD*

Dean, Lucas College and Graduate

School of Business

San José State University

Toks Omishakin*

Director

California Department of

Transportation (Caltrans)
Takayoshi Oshima

Chairman \& CEO

Allied Telesis, Inc.

Paul Skoutelas*

President \& CEO

American Public Transportation

Association (APTA)

Beverley Swaim-Staley

President

Union Station Redevelopment

Corporation

Jim Tymon*

Executive Director

American Association of

State Highway and

Transportation Officials

(AASHTO)

Larry Willis*

President (Deceased Nov. 2020)

Transportation Trades

Dept.,AFL-CIO

$*=$ Ex-Officio

** = Past Chair, Board of Trustees

\section{Directors}

Karen Philbrick, PhD

Executive Director

Hilary Nixon, PhD

Deputy Executive Director

Asha Weinstein Agrawal, PhD

Education Director

National Transportation Finance

Center Director

\section{Brian Michael Jenkins}

National Transportation Security

Center Director

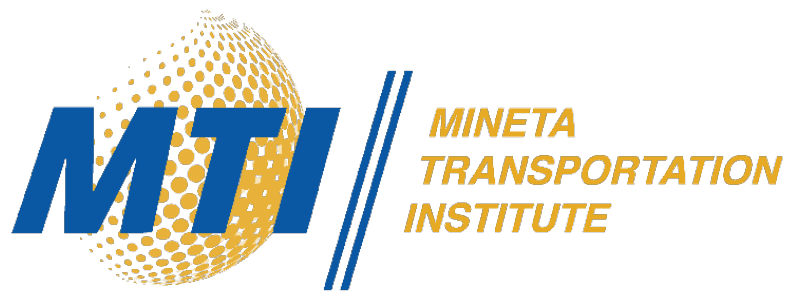

